TN 295

.04

No. 9157 





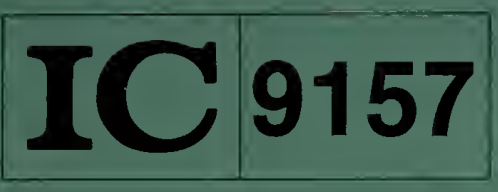

Bureau of Mines Information Circular/1987

\section{Suggested Minimum Performance Specifications for Underground Coal Mine Environmental Monitoring Systems}

By J. H. Welsh, A. F. Cohen, and J. E. Chilton 

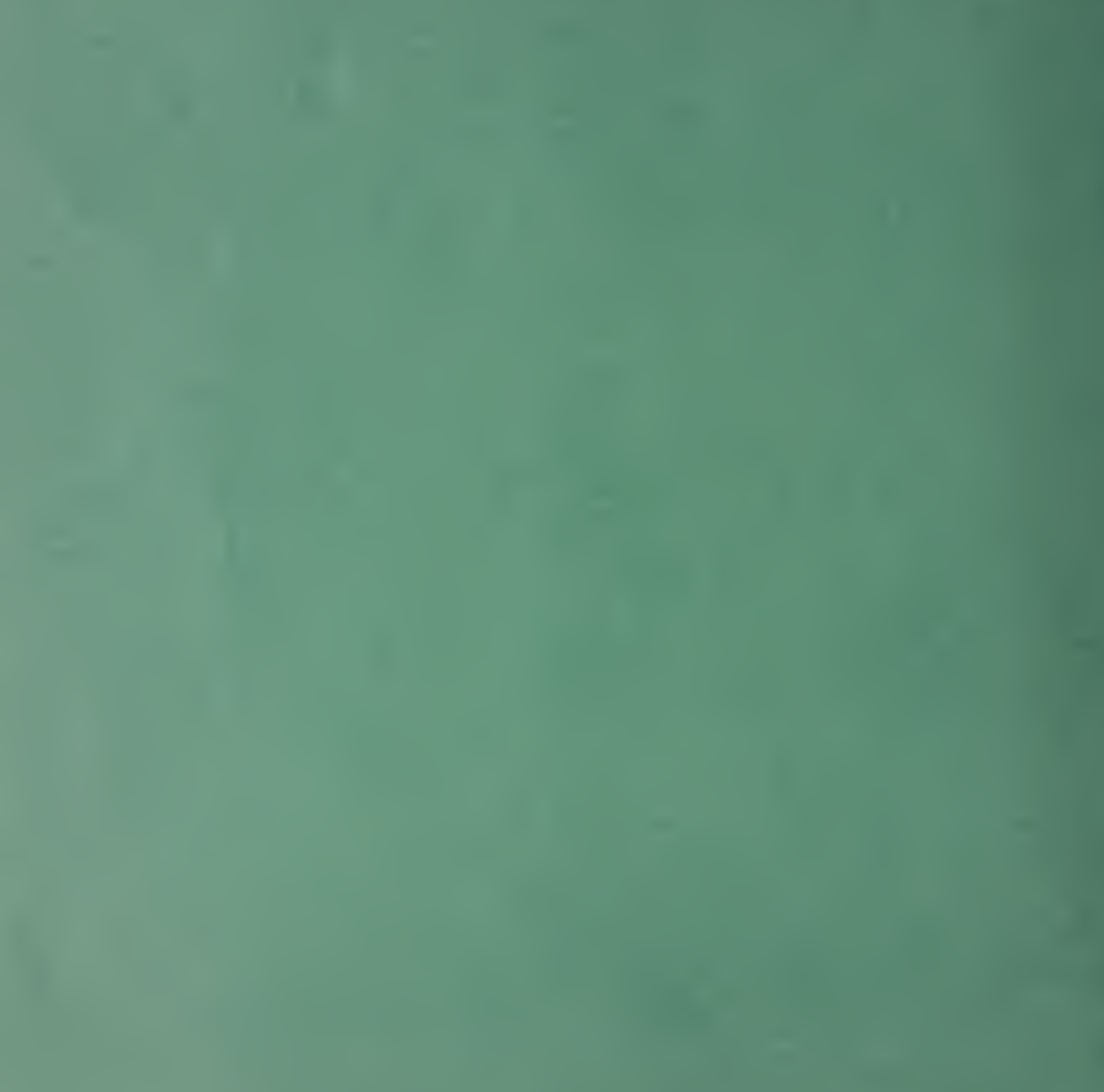
Information Circular 9157

\section{Suggested Minimum Performance} Specifications for Underground

Coal Mine Environmental

Monitoring Systems

By J. H. Welsh, A. F. Cohen, and J. E. Chilton

UNITED STATES DEPARTMENT OF THE INTERIOR

Donald Paul Hodel, Secretary

BUREAU OF MINES

David S. Brown, Acting Director 

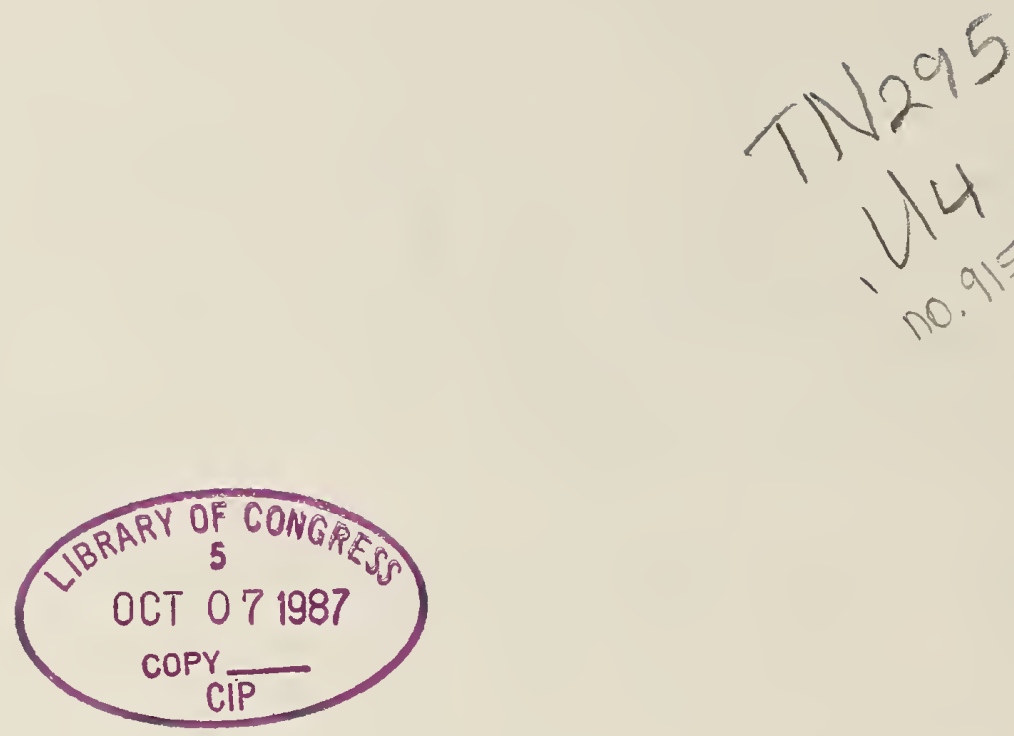

Library of Congress Cataloging in Publication Data:

Welsh, Jeffrey $H$.

Suggested minimum performance specifications for underground coal mine environmental monitoring systems.

(Information circular / United States Department of the Interior, Bureau of Mines ; 9157)

Bibliography: p. $27-28$.

Supt. of Docs. no.: 128.27:9157.

1. Coal mines and mining-Environmental aspects. 2. Environmental monitoring. I. Cohen, A. F. II. Chilton, J.E. III. Title. IV. Series: Information circular (United States. Bureau of Mines); 9157.

TN295.U4-

[TN803]

$622^{\prime} .42$

$87-600230$ 


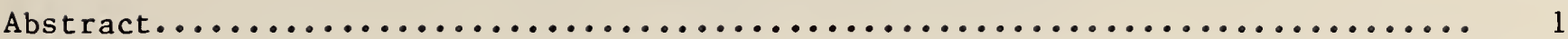

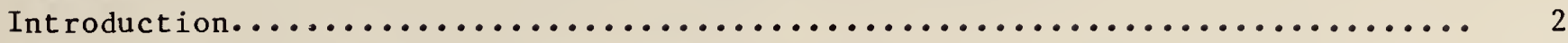

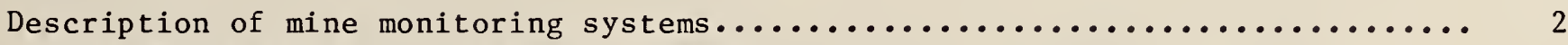

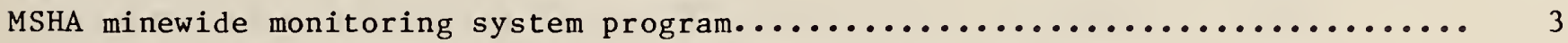

Current status of monitoring in the United States.....................

Potential uses of environmental mine monitoring systems............... 7

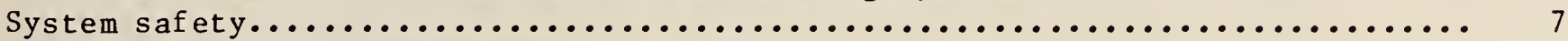

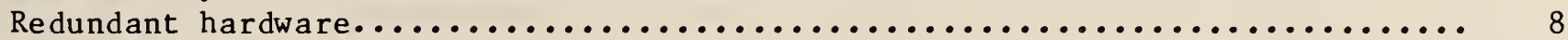

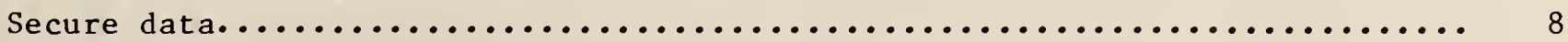

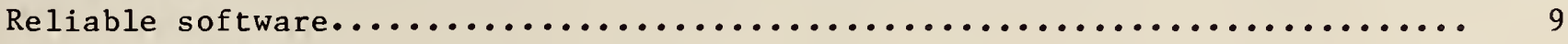

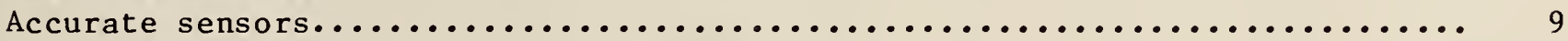

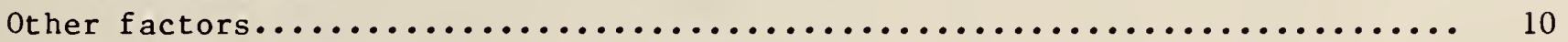

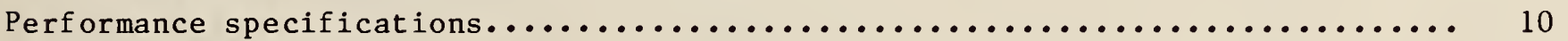

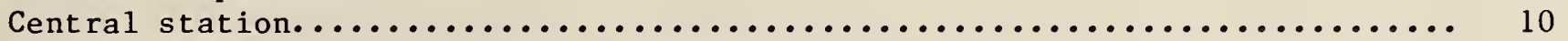

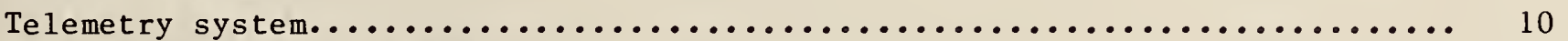

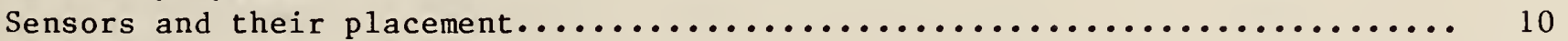

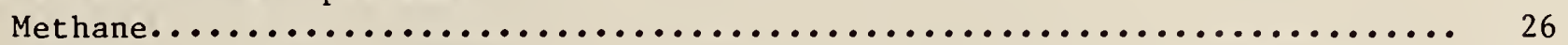

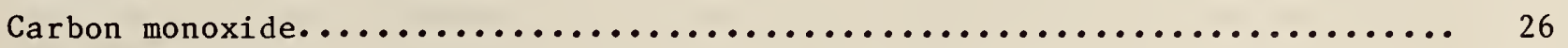

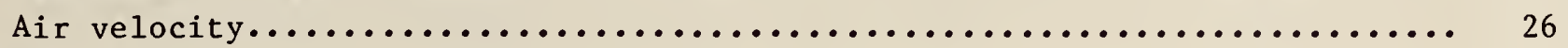

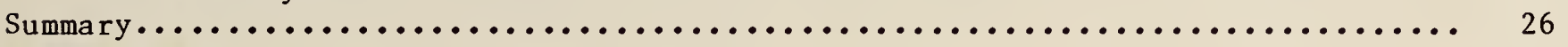

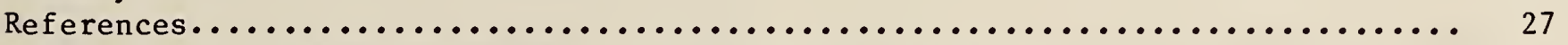

Appendix A.--Sensing techniques of environmental sensors................. 29

Appendix B.--Manufacturers of monitoring systems evaluated under the MSHA minewide monitoring system program................................. Appendix C.--Conditions for petitioning for modification of application of

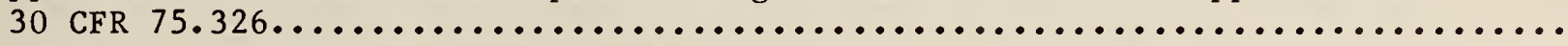
Appendix D.--Potential locations for fixed-point sensors based on 30 CFR Part

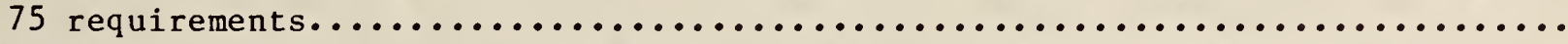
Appendix E.--Carbon monoxide sensor spacing criteria as defined by Factory

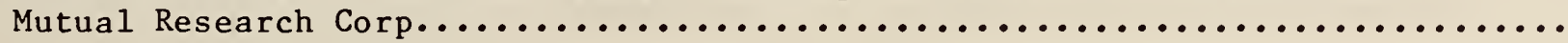

\section{ILLUSTRATIONS}

1. Configuration of monitoring system components...................

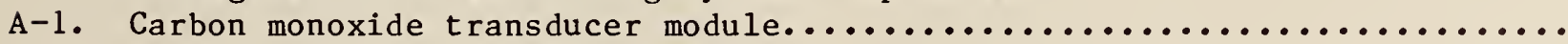

\section{TABLES}

1. MSHA letter classification for sensors and barriers................

2. Central station design, installation, operation, and maintenance........ Telemetry system design, installation, operation, and maintenance.......

4. Performance specifications for carbon monoxide transducer modules........

5. Performance specifications for methane transducer modules.............

6. Performance specifications for air velocity sensors................

D-1. Potential locations for fixed-point sensors.....................

E-1. Typical conditions in a conveyor belt haulageway $\ldots \ldots \ldots \ldots \ldots \ldots \ldots \ldots \ldots \ldots$

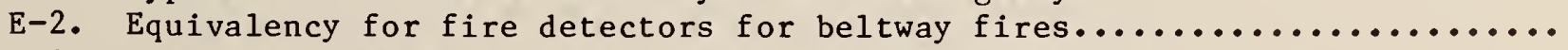

E-3. Spacing criteria for carbon monoxide sensors for beltway fires..........

E-4. Spacing criteria for carbon monoxide sensors for coal wall fires........ 
UNIT OF MEASURE ABBREVIATIONS USED IN THIS REPORT

$\begin{array}{llll}\mathrm{A} & \text { ampere } & \mathrm{mg} & \text { milligram } \\ { }^{\circ} \mathrm{C} & \text { degree Celsius } & \mathrm{mg} / \mathrm{m}^{3} & \text { milligram per cubic meter } \\ \mathrm{cfm} & \text { cubic foot per minute } & \mathrm{mH} & \mathrm{millihenry} \\ { }^{\circ} \mathrm{F} & \text { degree Fahrenheit } & \mu \mathrm{H} & \text { microhenry } \\ \mathrm{fpm} & \text { foot per minute } & \mathrm{min} & \text { minute } \\ \mathrm{ft} & \text { foot } & \mathrm{mph} & \text { mile per hour } \\ \mathrm{g} & \text { gram } & \mathrm{ppm} & \text { part per million } \\ \mathrm{h} & \text { hour } & \mathrm{psi} & \text { pound per square inch } \\ \mathrm{Hz} & \text { hertz } & \mathrm{s} & \text { second } \\ \text { in } & \text { inch } & \mathrm{V} & \text { volt } \\ \text { in } / \mathrm{h} & \text { inch per hour } & \mathrm{vol} \% & \text { volume percent } \\ \mathrm{m} & \text { meter } & \text { wh } & \text { week } \\ \mathrm{mF} & \text { millifarad } & \text { yr } & \text { year } \\ \mu \mathrm{F} & \text { microfarad } & & \end{array}$




\title{
SUGGESTED MINIMUM PERFORMANCE SPECIFICATIONS FOR UNDERGROUND COAL MINE ENVIRONMENTAL MONITORING SYSTEMS
}

\author{
By J. H. Welsh, ${ }^{1}$ A. E. Cohen, ${ }^{2}$ and J. E. Chilton ${ }^{3}$
}

\begin{abstract}
This Bureau of Mines report presents guidelines to be considered in the design, installation, and operation of environmental mine monitoring systems in underground coal mines so as to enhance safety in the U.S. mining industry. A review of the current status of mine monitoring in the United States is also provided.
\end{abstract}

\footnotetext{
1 Supervisory physical scientist.

${ }^{2}$ Physicist.

${ }^{3}$ Research chemist.

Pittsburgh Research Center, Bureau of Mines, Pittsburgh, PA.
} 


\section{INTRODUCTION}

Computerized mine monitoring had its beginning in the United States in the early 1970's. Since then, systems have evolved and been improved to a point where equipment is available commercially that can monitor the environment and equipment in underground mines. At the same time, computerized monitoring has become accepted by the mining industry as a means for increasing safety and production. Today, more than 50 U.S. underground mines have monitoring systems installed, and interest has been generated at many other operations. Many of the mines that have installed monitoring systems depend on them to provide miner safety. For example, a large number of systems monitor for fire along the belt conveyor entry with carbon monoxide sensors so that the belt entry can be used as an intake aircourse.

As more interest is generated in monitoring, and as mining operations become more dependent on monitoring systems to provide miner safety, there is an even greater need to ensure that these systems operate reliably and safely. In particular, several questions have been raised:

1. What design guidelines should be followed by system manufacturers to ensure software and hardware reliability?

2. Where should environmental sensors be placed in the mine to accurately depict the actual mine environment?

3. What maintenance procedures should be followed to keep monitoring systems in good operating condition?

This report addresses these questions by providing performance specifications and guidelines for environmental mine monitoring systems. It also covers the current status of mine monitoring in the United States, potential uses of environmental monitoring systems, and monitoring system safety. Even though computerized monitoring systems are capable of gathering information from equipment as well as from the environment, only environmental monitoring is addressed in this report.

\section{DESCRIPTION OF MINE MONITORING SYSTEMS}

Mine monitoring systems are electromechanical systems that remotely sense various environmental and operational parameters in a mine and transmit the data to a central location where they are analyzed and displayed. On the basis of this definition, a monitoring system can be discussed in terms of three basic functions: sensing, data transmission (or telemetry), and data analysis and display. In the case of monitoring and control systems, such as systems that automatically and remotely deenergize face equipment when the methane content at a specified location reaches a predetermined level, the control operation represents a fourth function.

Sensing can be divided into two general categories: environmental and production sensing. Environmental sensors are designed to measure various aspects of a mine's environment to assist in maintaining safe conditions for underground personnel. The parameters that are of concern are carbon monoxide, methane, and air velocity. These sensors are used to detect and locate potentially hazardous conditions such as fires, methane buildups, and ventilation failures so that appropriate measures can be taken. Production sensors are used to monitor the operating status of various pieces of underground equipment to detect production bottlenecks, equipment failures, and maintenance requirements. Examples include conveyor belt, pump, and face equipment operation. This report only addresses environmental monitoring for carbon monoxide, methane, and air velocity.

The sensor output can be a simple status indication, called a binary, contact closure, or status output (high-low, open-closed), or it can be a continuously variable function of time, called analog output (air velocity, methane concentration, etc.). While the continuously variable data can provide significantly more 
information than the simple status data, how much more depends on the accuracy of the measurements. The sensing or measurement techniques for carbon monoxide, methane, and air velocity sensors are discussed in appendix A.

Telemetry is the process of transmitting data output from the sensors to the central station on the surface. Since it is generally not feasible to run a separate conductor or conductor pair to each sensor, telemetry systems typically use several remote stations or "outstations," each accepting and encoding the output of a number of sensors and transmitting the encoded data along a common cable to the central station. The two most common encoding techniques are (1) frequency domain multiplexing and (2) time domain multiplexing. Frequency domain multiplexing has the advantage that data from all monitoring points are received at all times, although the number of monitoring points is limited by the overall bandwidth of the system. Time domain multiplexing can be expanded to accommodate as many monitoring points as desired; however, each point is sampled only intermittently since the system interrogates the monitoring points sequentially. The cycle time, or the time between successive samplings of the same point, is the time the system requires to interrogate all the monitoring points.

Time-multiplexed systems of ten transmit data in digital format, $i, e$. , a series of high-low state indications is transmitted that represents the monitoring point status. A common technique to accomplish this transmission is to use frequency shift key (FSK) encoding. This encoding process uses two different frequencies to represent the high and low states, rather than high- and low-level signals of the same frequency. The FSK encoded data are less affected by noise on the transmission line than data in simple high-low digital format. In addition, current signal detection techniques make it very easy to detect dual-frequency signals in the presence of noise.

The third basic function of a monitoring system is analysis and display of the measured data. These operations are normally accomplished by a computer in an aboveground central location. Most systems have the ability to trigger audiovisual alarms if a sensor detects that its predetermined threshold has been exceeded. In addition, most systems provide hard copy documentation of the alarms and display the actual values detected by the sensors on video display terminals (VDT). Color graphics are usually available to enhance the interface with the user. These computer-based systems can have the added capability of data storage for trend analysis, record keeping, and reporting.

\section{MSHA MINEWIDE MONITORING SYSTEM PROGRAM}

In June 1982, the Mine Safety and Health Administration (MSHA) began accepting applications for minewide monitoring system (MWMS) evaluations, and sensor and barrier classifications. This established a means for manufacturers to have their monitoring equipment evaluated for use in both fresh and return air.

Before that time, it was not possible to obtain general MSHA approval for operating a computerized mine monitoring system underground in return air because MSHA had no schedule under which it could approve the systems. Systems installed in U.S. underground coal mines before
1982 were installed on an individual basis with the approval of the MSHA district manager, and only in fresh air up to the last open crosscut.

The MWMS program evaluates mine monitoring systems for electrical and intrinsic safety; performance of the system is not considered. Intrinsic-safety requirements are only applied to equipment interfacing with, and located in, gassy areas. Equipment located in fresh air must only meet general electrical safety requirements.

Figure 1 shows possible configurations of mine monitoring system components. 


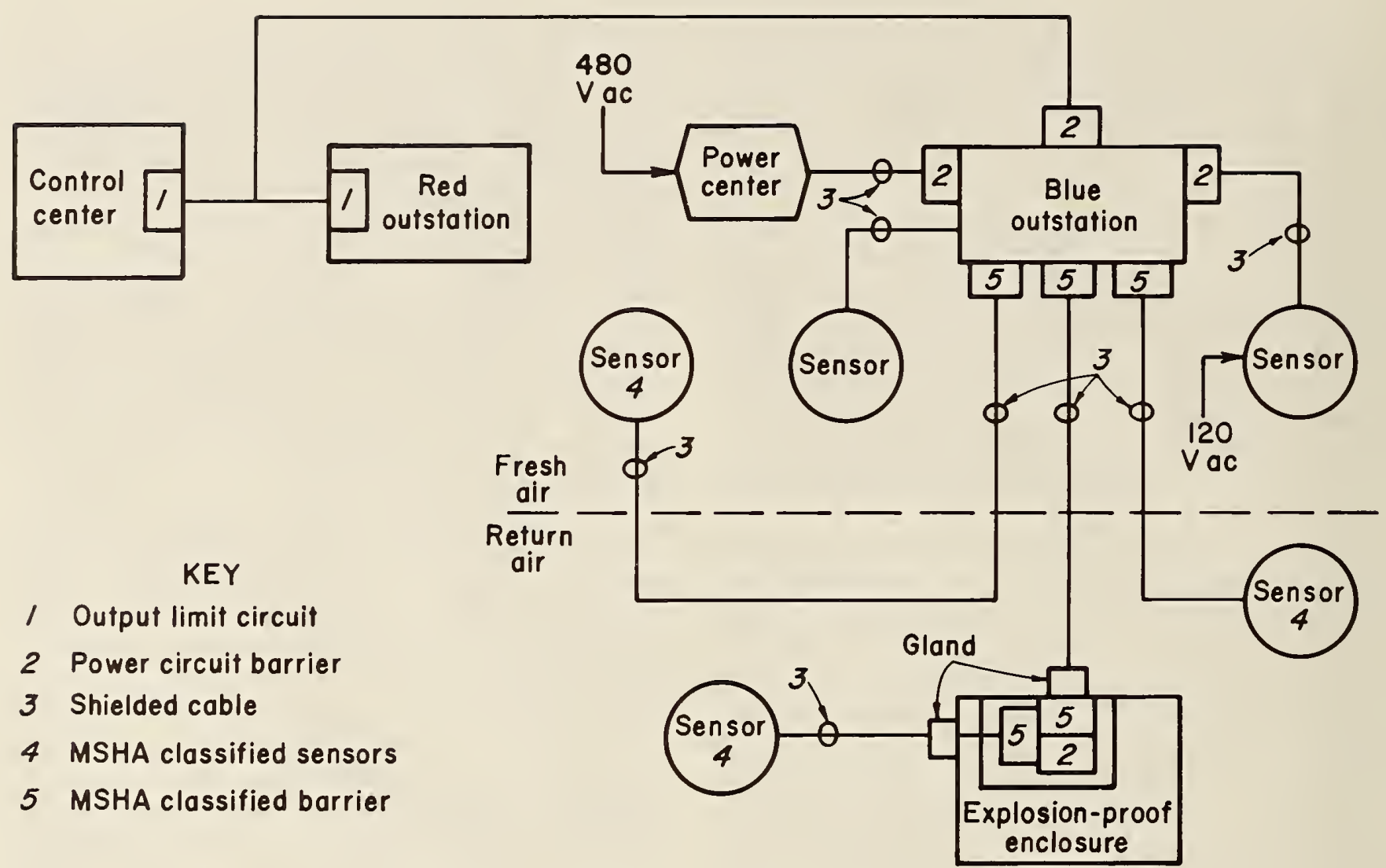

FIGURE 1.-Configuration of monitoring system components.

Outstations must be located in fresh air, since they are not considered intrinsically safe, and they must be either red or blue in color. All sensor circuits directly connected to red outstations must be located in fresh air, while sensor circuits connected to blue outstations may be located in gassy areas or may be connected to high-voltage devices.

Barrier devices are used to isolate power circuits and to provide instrinsically safe circuits. Two types of barriers are included in the MWMS program-power circuit barriers and letter class barriers. Power circuit barriers allow connection of a blue outstation to circuits whose voltage may exceed the maximum allowable input of the letter class barriers. Letter class barriers allow connection of a blue outstation to circuits located in gassy areas. Letter class barriers are classified according to their output voltage and current. Both types of barriers are located in blue outstations.
Sensors located in gassy areas must also be classified by a letter classification according to their effect on intrinsic safety, considering the maximum barrier energy output with safety factors applied. Intrinsic safety of sensors and sensor cabling located in gassy areas is assured when a sensor circuit is connected to a barrier of the same class. Table $1(1)^{4}$ shows MSHA sensor and barrier classifications.

MSHA-certified explosion-proof enclosures must be used to include circuits and components in the system that are not intrinsically safe yet are located in gassy areas. A letter class barrier, of the same classification as the letter class barrier at the blue outstation, must be used to protect the wiring connecting the circuits within the enclosure with the rest of the system. Letter

\footnotetext{
${ }^{4}$ Underlined numbers in parentheses refer to items in the list of references preceding the appendixes.
} 
TABLE 1. - MSHA letter classification for sensors and barriers

\begin{tabular}{|c|c|c|c|c|}
\hline \multirow[b]{2}{*}{$\mathrm{Cl}$ ass } & \multicolumn{2}{|c|}{ Barrier values } & \multicolumn{2}{|c|}{ Sensor values } \\
\hline & $\begin{array}{c}\text { Nominal output } \\
\text { voltage, } \mathrm{V}\end{array}$ & $\begin{array}{c}\text { Maximum output } \\
\text { current, A }\end{array}$ & $\begin{array}{c}\text { Maximum } \\
\text { capacitance }\end{array}$ & $\begin{array}{l}\text { Maximum } \\
\text { inductance }\end{array}$ \\
\hline A....... & 5 & 3.0 & $5 \mathrm{mF}$ & $100 \mu \mathrm{H}$ \\
\hline 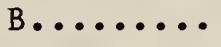 & 5 & 1.0 & $5 \mathrm{mF}$ & $1 \mathrm{mH}$ \\
\hline C........ & 10 & 3.0 & $60 \mu \mathrm{F}$ & $100 \mu \mathrm{H}$ \\
\hline D....... & 10 & 1.0 & $60 \mu \mathrm{F}$ & $1 \mathrm{mH}$ \\
\hline$E \ldots \ldots \ldots$ & 12 & 3.0 & $30 \mu \mathrm{F}$ & $100 \mu \mathrm{H}$ \\
\hline$F \ldots \ldots \ldots$ & 12 & 1.0 & $30 \mu \mathrm{F}$ & $1 \mathrm{mH}$ \\
\hline G........ & 15 & 1.25 & $15 \mu \mathrm{F}$ & $300 \mu \mathrm{H}$ \\
\hline H....... & 20 & .7 & $7 \mu \mathrm{F}$ & $1 \mathrm{mH}$ \\
\hline I....... & $20 / 10$ & $0.7 / .1$ & $1 \mu \mathrm{F}$ & $800 \mu \mathrm{H}$ \\
\hline $\mathrm{J}_{\ldots} \ldots \ldots$ & 25 & .3 & $3 \mu \mathrm{F}$ & $10 \mathrm{mH}$ \\
\hline K........ & 30 & .1 & $1 \mu \mathrm{F}$ & $15 \mathrm{mH}$ \\
\hline L....... & 18 & 1.0 & $10 \mu \mathrm{F}$ & $\mathrm{l} \mathrm{mH}$ \\
\hline$z^{1} \ldots \ldots \ldots$ & & & & \\
\hline
\end{tabular}

${ }^{1}$ Reserved for nonelectrically operated switch contacts, thermocouples, resistance temperature devices, etc., and may be connected to any MSHA letter class barrier.

class barriers are also used to interface with classified sensors located outside the enclosure. A power circuit barrier must be used when circuits within the enclosure are monitored, controlled, or used to supply power to the system.

Data transmission lines that connect outstations and the central station are not accepted by MSHA as intrinsically safe and are considered a possible electrical shock hazard. The normal operating voltage of data transmission lines must not exceed $60 \mathrm{~V}$ per conductor to ground.
If batteries are used underground to provide continued system operation in the event of loss of mine power, the battery source must be disconnected and electrically isolated upon loss of mine ventilation. This can be done automatically by ventilation sensing or manually from the central station.

Manufacturers of monitoring systems that have been evaluated under the MSHA Minewide Monitoring System Program are listed in appendix B. Foose (1) gives further information on the requirements of the Minewide Monitoring System Program.

\section{CURRENT STATUS OF MONITORING IN THE UNITED STATES}

Mine monitoring systems installed in the United States vary in their use and in their capabilities. Some systems monitor several points; others monitor and control whole mine complexes involving over 1,000 points. Likewise, the systems vary from personal-computer based devices with a monochrome video display terminal (VDT), no data storage, and the ability to support a limited number of outstations and sensors, to 16-bit computers with sophisticated color graphics, longterm data storage, analysis and trending, and the ability to support many outstations and sensors.

The majority of the over 50 systems installed in U.S. underground mines monitor at least 1 environmental parameter. Environmental parameters being monitored include carbon monoxide, methane, air velocity, temperature, humidity, absolute pressure, and smoke; carbon monoxide is the most common. A number of mine operators have been granted a variance from the Code of Federal Regulations (CFR)' mandatnrv standard, $30 \mathrm{CFR}$ (2), 
Part 75.326, Aircourses and Belt Haulage Entries, resulting in widespread use of carbon monoxide sensing. This was also a major reason for the rapid growth of mine monitoring in the $1980^{\prime} \mathrm{s}$.

The mandatory safety standard states that the air coursed through belt haulage entries must be limited to the amount necessary to provide adequate oxygen and to ensure the air contains less than $1 \%$ methane; and that such air cannot be used to ventilate active working places. Under certain circumstances, on a case-bycase basis, MSHA has allowed mine operators to use the belt haulage entry as an intake aircourse to ventilate active working places, with certain restrictions, provided carbon monoxide is monitored continuously along the belt haulage entry with a computerized monitoring system to provide rapid fire detection. Specific guidelines for the use of the belt haulage entry for intake air are listed in appendix C. As of mid-1986, 40 mines (3) had received a variance of 30 CFR $75 . \overline{3} 26$ based on the use of a carbon monoxide mine monitoring system.

Besides carbon monoxide monitoring, the use of other environmental sensors in the United States has been limited because mine operators have not been able to receive a direct monetary benefit from their installation, since in most cases MSHA has not allowed a tradeoff for a requirement in a mandatory standard. This may change in the future depending on the outcome of the current rewrite of $30 \mathrm{CFR}$ mandatory standards for the ventilation area. (See the next section of this report.) A mine operator should, however, benefit from environmental monitoring through increased safety, provided the system is maintained in an operational condition.

Other variances of mandatory standards based on the installation of a mine monitoring system have been filed and granted. A petition for a variance can be considered if an alternative method of achieving the result of the standard exists that will at all times guarantee no less than the same measure of protection afforded by the standard. Other regulations besides 75.326, in which a petition has been filed to use a mine monitoring system, are listed below.

75.305 Weekly examination for hazardous conditions.--This section requires weekly inspections of at least one entry of each intake and return aircourse in its entirety, both for methane and for compliance with the mandatory health and safety standards. Typical petitions state that because of poor roof conditions it is not possible to travel the aircourses in their entirety, and offer checkpoint measurements as an alternative. Continuous methane measurements (75.305) could be made with a monitoring system at these checkpoints. Airflow measurements required by 75.306 could also be made with the same system.

75.312 Air passing through abandoned, inaccessible, or robbed area.--This section requires that air that has passed through an abandoned area or an area that is inaccessible or unsafe for inspection not be used to ventilate any working place in the mine. The petitioner proposes to monitor the air passing through these areas with an envitronmental monitoring system in order to use the air to ventilate active working areas.

75.1103-4(a) Automatic fire sensor and warning device systems; installation; minimum requirements.--This section requires that automatic fire sensor and warning device systems provide identification of fire within each belt flight. A petition proposes to use a carbon monoxide monitoring system for the fire detection system.

75.1105 Housing of underground trans former stations, battery-charging stations, substations, compressor stations, shops, and permanent pumps.--This section requires that aircurrents used to ventilate structures or areas enclosing electrical installations be coursed directly to the return. Petitions requested to use the air ventilating transformer stations to ventilate active working areas. They proposed monitoring for carbon monoxide in order to do so. 
POTENTIAL USES. OF ENVIRONMENTAL MINE MONITORING SYSTEMS

A number of potential uses for environmental mine monitoring systems may provide increased mine safety. Some of these have been identified in a draft, revised safety standard for ventilation in underground coal mines that has been circulated for public comment (4). They include--

1. Monitoring mine ventilating pressure for each surface mine fan.

2. Monitoring carbon monoxide at underground electrical installations.

3. Monitoring carbon monoxide where intake air is being heated by liquefied fuel systems.

4. Monitoring carbon monoxide in belt entries so those entries can be used as intakes ( 75.326 variance).

5. Monitoring carbon monoxide and methane in belt entries used as returns.

6. Monitoring carbon monoxide, methane, and air velocity in any mine in which the methane concentration in air in any given main or submain return aircourse exceeds $1 \%$.

7. Monitoring methane during each shift that coal is produced and at intervals not to exceed $4 \mathrm{~h}$ at locations specified for the on-shift examination for hazards.

8. Monitoring methane and air velocity at locations specified for the weekly examination.

9. Monitoring carbon monoxide, methane, and air velocity for evaluation of return aircourses developed before 1970 .

There are other mine scenarios in which continuous environmental monitoring may impact mine safety. One is for mines that use two-entry longwall mining. Under adverse geologic conditions, the two-entry technique has reduced the occurrence of pressure bumps, roof falls, and other ground control problems during mining operations. However, in emergency situations, evacuation of miners is limited, and substantial measures, such as environmental monitoring, are needed. Recommendations by the MSHA Task Force on longwall mining ( $\underline{5}$ ) for monitoring for this scenario include--

1. Insta11 an environmental monitoring system in the intake escapeway of all longwal1 developments and longwall panels when both designated escapeways are ventilated by one continuous split of air. The sensing devices in this monitoring system will be low-level carbon monoxide monitors or sensors for another product of combustion that are no less effective.

2. Insta11 an environmental monitoring system in the belt haulage entry whenever belt air is used to ventilate active working places or the belt entry is used as a return aircourse. The system would utilize low-level carbon monoxide monitors or sensors for another product of combustion that are no less effective. When the belt entry is used as a return aircourse, methane monitors would be used.

3. Methane monitoring and automatic deenergization of electric equipment must be used when conditions exist where methane gas could be backed up the intake entries to points beyond the normal location of nonpermissible electrical equipment.

In the future, as mines become deeper and more complex, environmental monitoring will be a necessity to provide a safe and healthy workplace for miners.

\section{SYSTEM SAFETY}

The question of "How safe is safe?" has perplexed people for many years. This question must not be taken lightly since a system must monitor methane, with the possibility of an explosion if high concentrations are not detected, and must detect a fire and alarm fast enough to alert miners to evacuate a mine. For 
environmental mine monitoring systems to provide mine safety, they must be designed with reliability and safety in mind and must be adequately tested and properly installed, operated, and maintained. If there are shortcomings in any of these areas, on the part of either the manufacturer or the mine operator, the potential exists for serious safety consequences, especially when miner safety depends on the monitoring system.

The Bureau of Mines has investigated monitoring system safety through in-house and contract research. Some of the findings are presented here.

\section{REDUNDANT HARDWARE}

The reliable operation of mine monitoring system hardware was investigated through an interagency agreement with Rome Air Development Center, Reliability and Maintainability Engineering Section (6), and through a contract with West Virginia University (WVU) (7). Based on this research, it was concluded that complete duplication or even triplication of the entire monitoring system should be given serious consideration. Duplication would have to be done with great care when interconnecting the duplicates to ensure that one failure does not cause the entire system to fail. Duplication would be expensive but would provide more insurance that no alarms pass undetected because of system hardware or software parts failure.

The central processor unit (CPU) should be at least duplicated with output comparators to detect system disagreements. This increases the safety of the system by not allowing hardware errors to go undetected. However, reliability is not increased, and the system would probably be out of service more than a single CPU system. A fault-tolerant CPU system would increase the reliability of the monitoring system as well as provide the system checks for operating safety. A CPU such as this would actually be composed of three CPU's with voting outputs. If two of the three CPU's (each running independent versions of the software) provided a common output, that majority output would be the command of record, and the odd command would be flagged as an error.

WVU a1so recommends that underground sensors should be duplicated, if the loss of data from one location could immediately kill people. The recommendation for duplicate sensors, of course, depends on the type of sensor, the spacing between sensors, and the velocity of air movement.

The communication system should be duplicated. That is, independent cabling for the dual sensors should be used, preferably in different paths. These paths should be separated completely, even to the point of running one underground and the other on the surface. This would prevent a complete communication failure if one cable is damaged by accident, roof fall, or fire.

\section{SECURE DATA}

Another problem is data security, the error rate for information transmissions. Most errors are caused by electromagnetic noise, which is quite severe in a mining environment. The problem is not so much that an error is transmitted, but that an error in transmission goes undetected because of the noise on the transmission line. The sensitivity to erroneous data transmission depends on factors such as the cable used, local noise field, length of cable run, and data formating. Bureau research indicates that the maximum transmission distance for one undetected random error per year ranges from 1.3 to 6.8 miles in an average noise field, and from 0.1 to $0.6 \mathrm{mile}$ in an estimated maximum noise field. Since cable runs are frequently several miles, one can expect occasional undetected transmission errors.

Communication protocols should be such that when a message is transmitted from a CPU-based devise to a sensor, the sensor should always echo what it received (its address, data received, or command received) in order for the transmitting device to verify that the command was received. This should not be a userimplemented option, but should be automatic. Techniques for detecting erroneous data transmission have been devised, 
principally by computer manufacturers. IBM's ${ }^{5}$ synchronous data link control (SDLC) and Digital Equipment Corp.'s digital data communication message protocol (DDCMP) have been identified by the University of $0 \mathrm{klahoma} \mathrm{(8)}$ as promising for mining environment use. The use of shielded cable also provides increased data security from electromagnetic noise.

\section{RELIABLE SOFTWARE}

Proper software design is difficult to ensure. It is difficult to be certain that all bugs have been detected and removed from the software. Manufacturer testing of software typically does not test all possible scenarios that may be encountered in the field. An example would be how the software responds during an emergency when multiple alarms are occurring simultaneously.

Probably the best indication of whether the bugs have been worked out of the software is how long the manufacturer has had its software in the field. The longer the software has been in use, the greater the probability the bugs have been worked out.

Optimally, to reduce the chance of software errors, software should be developed by two independent programmers who develop independent versions of software to do the same job. A coal operator would then purchase two processors, each running a different version of the software with comparison of results.

To meet the need for a method of testing monitoring system software without actual installation in an underground coal mine, or to accelerate this testing, a monitoring system-software test apparatus was developed by WVU under a Bureau contract (9). The objective of this contract was to develop a monitoring system testing tool that would both test existing monitoring systems for use in underground coal mines, and also be flexible enough to test systems that will be available in the future.

\footnotetext{
5 Reference to specific products does not imply endorsement by the Bureau of Mines.
}

The test apparatus provides the capability of performing evaluation of monitoring systems such as the communication saturation point, which is extremely important especially during emergency conditions, to evaluate delay time from alarm condition to alarm annunciation. All of the software in the monitoring system can be exercised, including software modules normally executed only during emergency situations. The test apparatus also provides for consistent testing of different monitoring systems, by allowing strict control of the test procedure and mine parameters.

The MSHA Approval and Certification Center has expressed interest in this apparatus.

\section{ACCURATE SENSORS}

Sensors are a critical element in mine monitoring systems since they provide the input data. If the input data are not correct or not representative of the required measurement, the entire monitoring process is meaningless. One problem with sensors is that their output represents the response of the sensor to a number of parameters, in addition to the one that is to be measured. Examples are the response of the sensor to changes in temperature, the poisoning of sensors by other gases in the mine, or the situation when carbon monoxide sensors respond to fire, blasting, and diesel emissions. The critical problem relates to the ability of the sensor to actually measure the parameter of interest. In particular, ventilation monitoring systems use point air velocity measurements to represent the total airflow at a cross section in the mine. The total airflow is determined either from an empirically derived factor and the point measurement, or from actual calibration of the cross section. The problem is further complicated because the only safe location for the sensor, to prevent damage from mining operations, is on the rib or roof in the low-flow boundary layer. It is possible to have large changes in the overall airflow with little or no change in the velocities in the boundary layer and, consequently, in the sensor output. 
The Bureau has conducted sensor location strategy experiments and has deve1oped guidelines for sensor placement. These are discussed in the section entitled "Sensors and Their Placement."

\section{OTHER FACTORS}

Other factors affecting system safety are the manufacturer's quality control procedures; what are the inspection and/or quality assurance policies? Also, are the manufacturers aware of, and do they use, components and assembly practices suitable for the mine environment, such as MIL-SPEC electronic components, NEMA 4 enclosures, conformal coating of circuit boards, etc.?

A mine operator should only consider reputable companies when choosing a monitoring system supplier. Previous experience and references should be considered, and other mine operators who have a system should be asked if they are satisfied with the system and service. Appendix $B$ lists monitoring system manufacturers who have had their system evaluated by MSHA under the MWMS Program. This list is a good place to start when looking for a system supplier.

If all the recommendations for system safety discussed in this section were followed, the resultant system would be too costly. Therefore, a mine operator must weigh the costs and benefits of the various alternatives. Minimum performance specifications and guidelines for monitoring system implementation and safety are listed below.

\section{PERFORMANCE SPECIFICATIONS}

Minimum performance specifications and guidelines for design, installation, and operation of mine monitoring systems are provided in this section to (1) help mine operators in selecting a monitoring system for their mine, (2) minimize the application of poorly designed monitoring systems in mines, and (3) provide assistance in the installation and operation of mine monitoring systems.

For this discussion, the components of a mine monitoring system are divided into three areas: central station, telemetry, and sensor. Within each component area, design, installation, and operation of the equipment are discussed. The performance specifications have been deve1oped from Bureau field and laboratory research. References 6-13 contain additional information.

\section{CENTRAL STATION}

The central station is typically 1ocated on the surface and consists of a computer(s) with software, video display terminal(s) with keyboard, and printer(s). This equipment gathers data from underground sensors, analyzes them, and displays them to an operator. Table 2 lists central station design, installation, operation, and maintenance specifications.

\section{TELEMETRY SYSTEM}

The telemetry system consists of the cable connecting each outstation to the central station, the other outstations, and the communication protocol. The majority of this equipment is located in the mine and, therefore, should be suited for the mine environment. Table 3 lists telemetry system design, installation, operation, and maintenance specifications.

\section{SENSORS AND THEIR PLACEMENT}

Sensors are a critical element in mine monitoring systems since they provide the input data, while being physically 1ocated in the harsh mine environment. For environmental monitoring, three sensor types are of main concern: carbon monoxide, methane, and air velocity. In tables 4, 5, and 6, measurement requirements, environmental requirements, and maintenance and other requirements for the performance specifications of each of the three sensor types are discussed. 


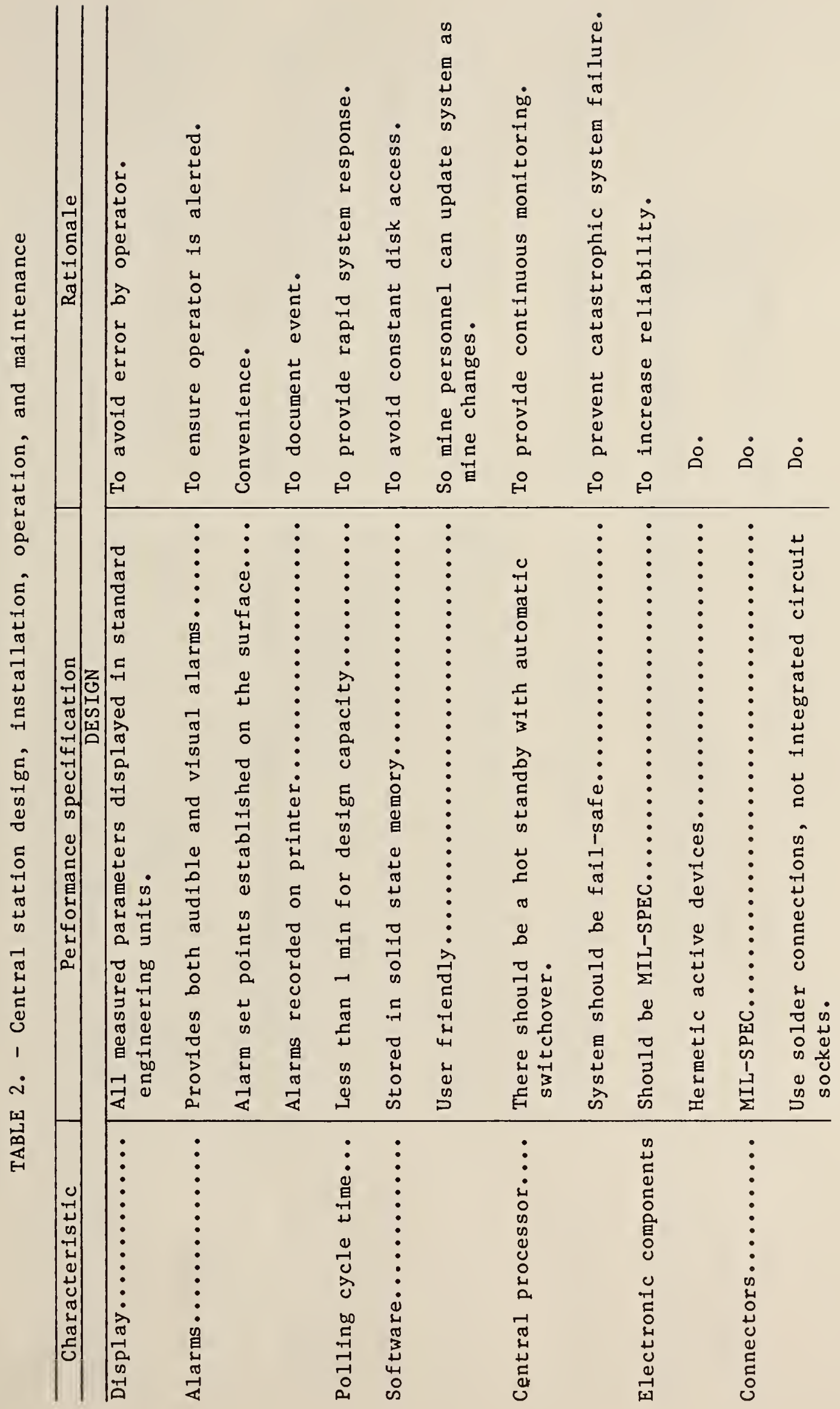




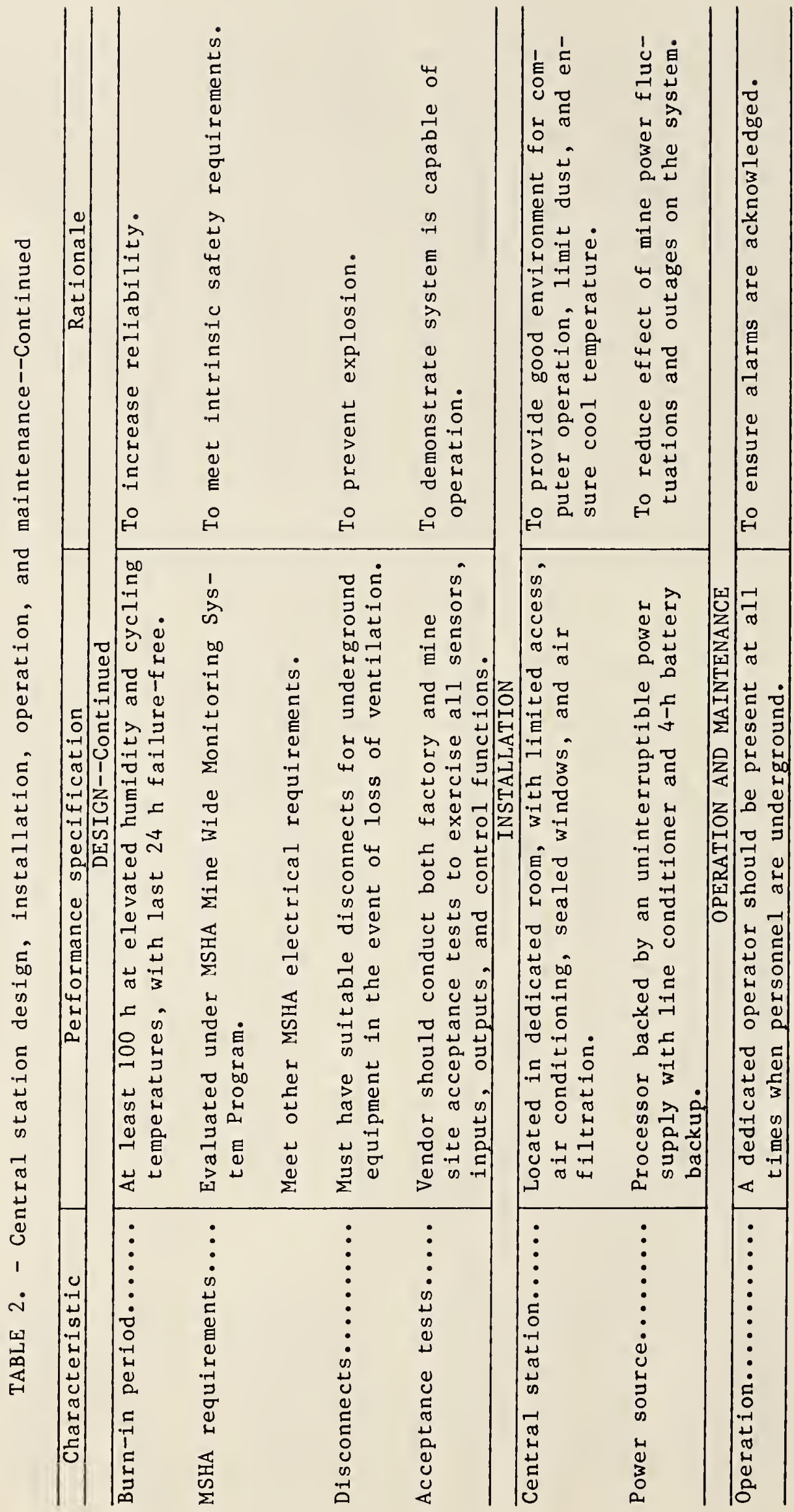




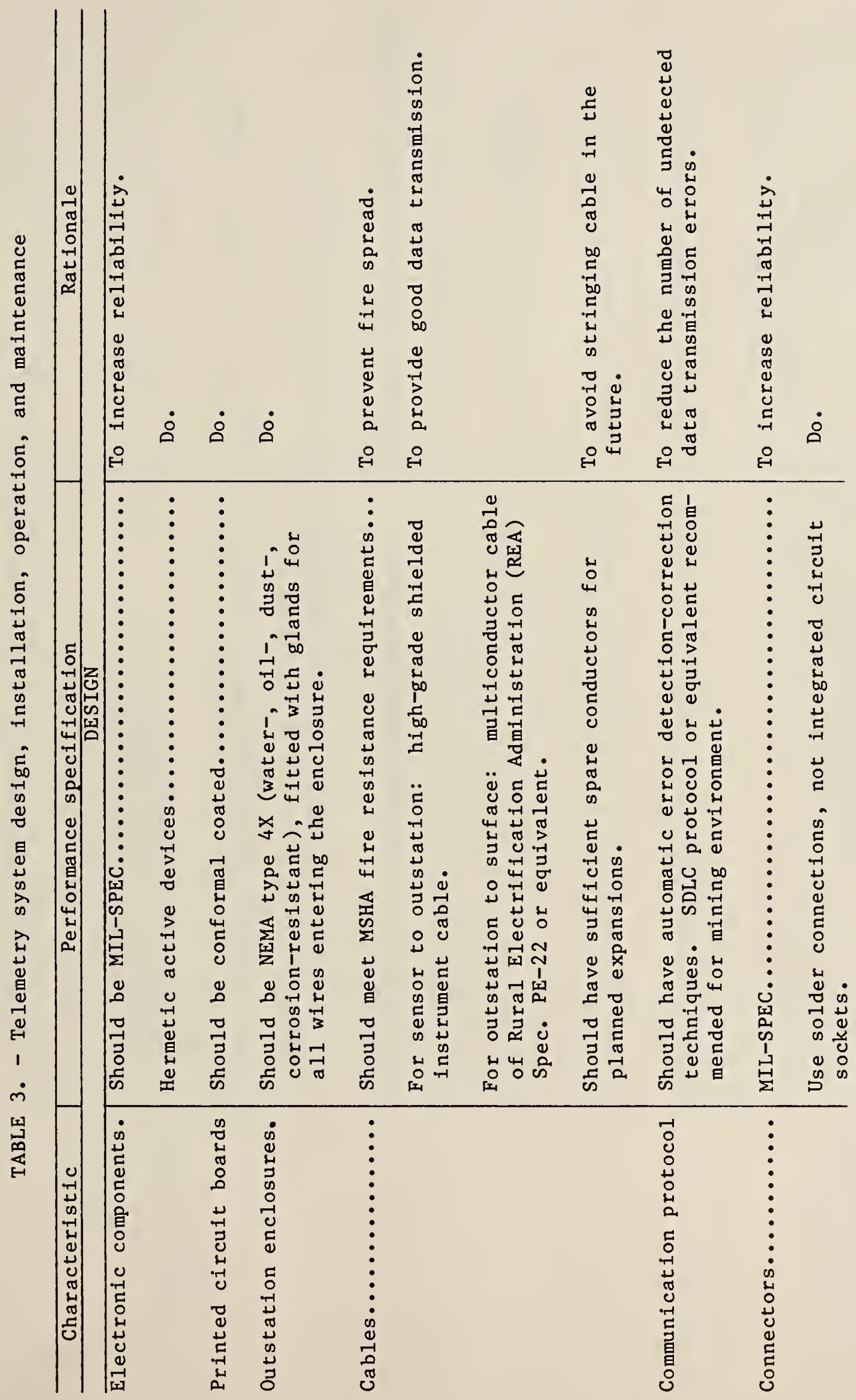




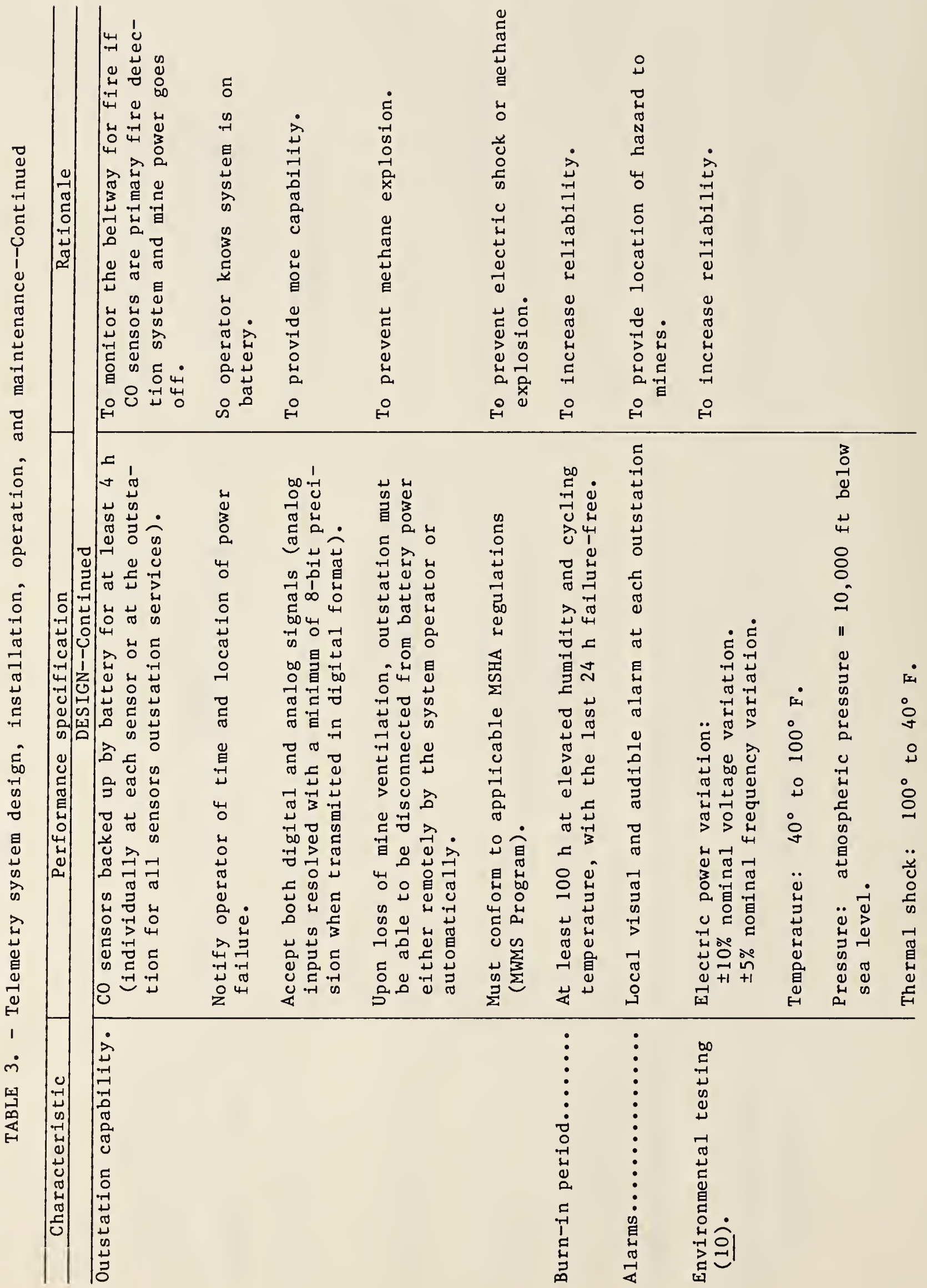




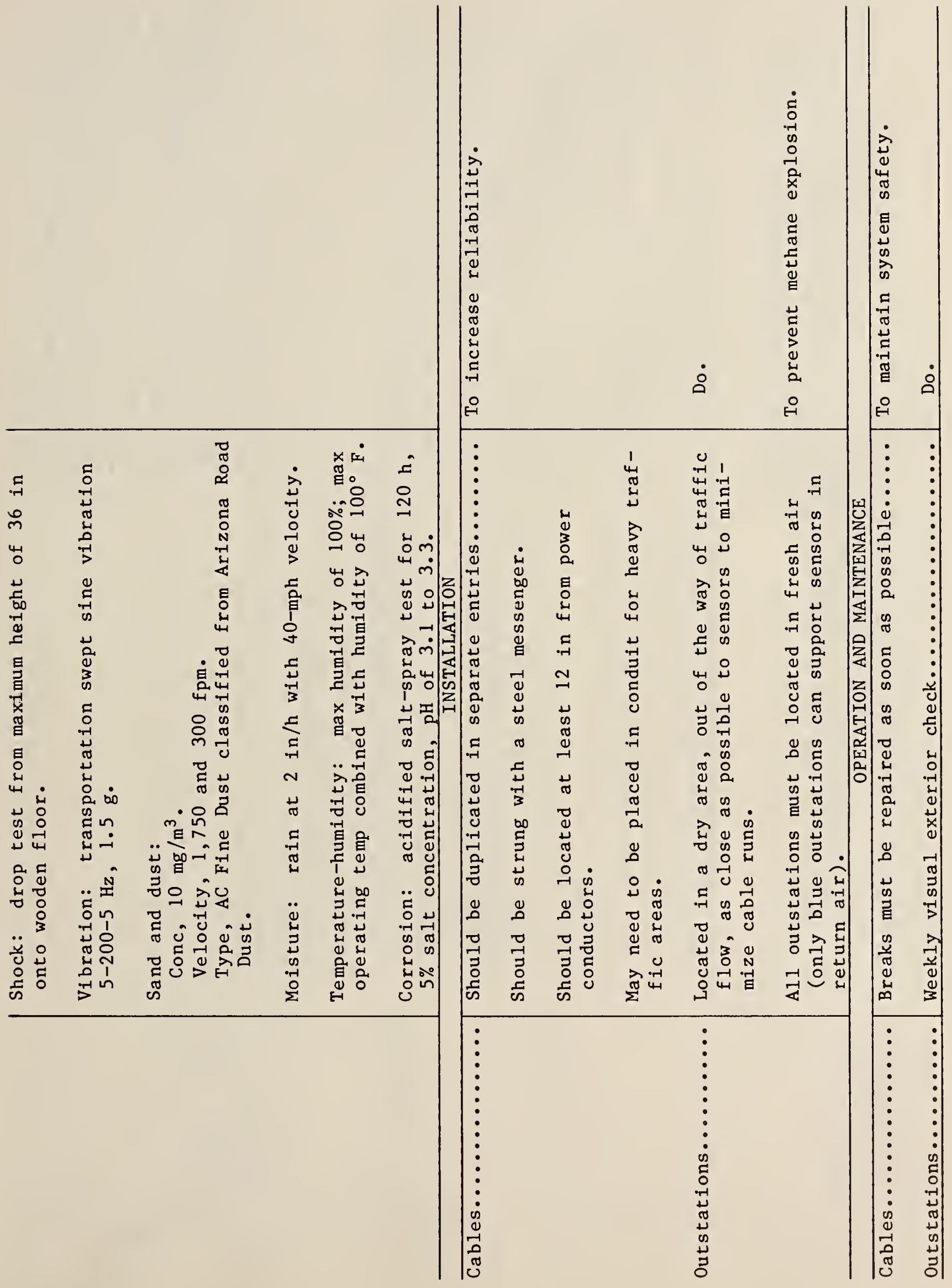




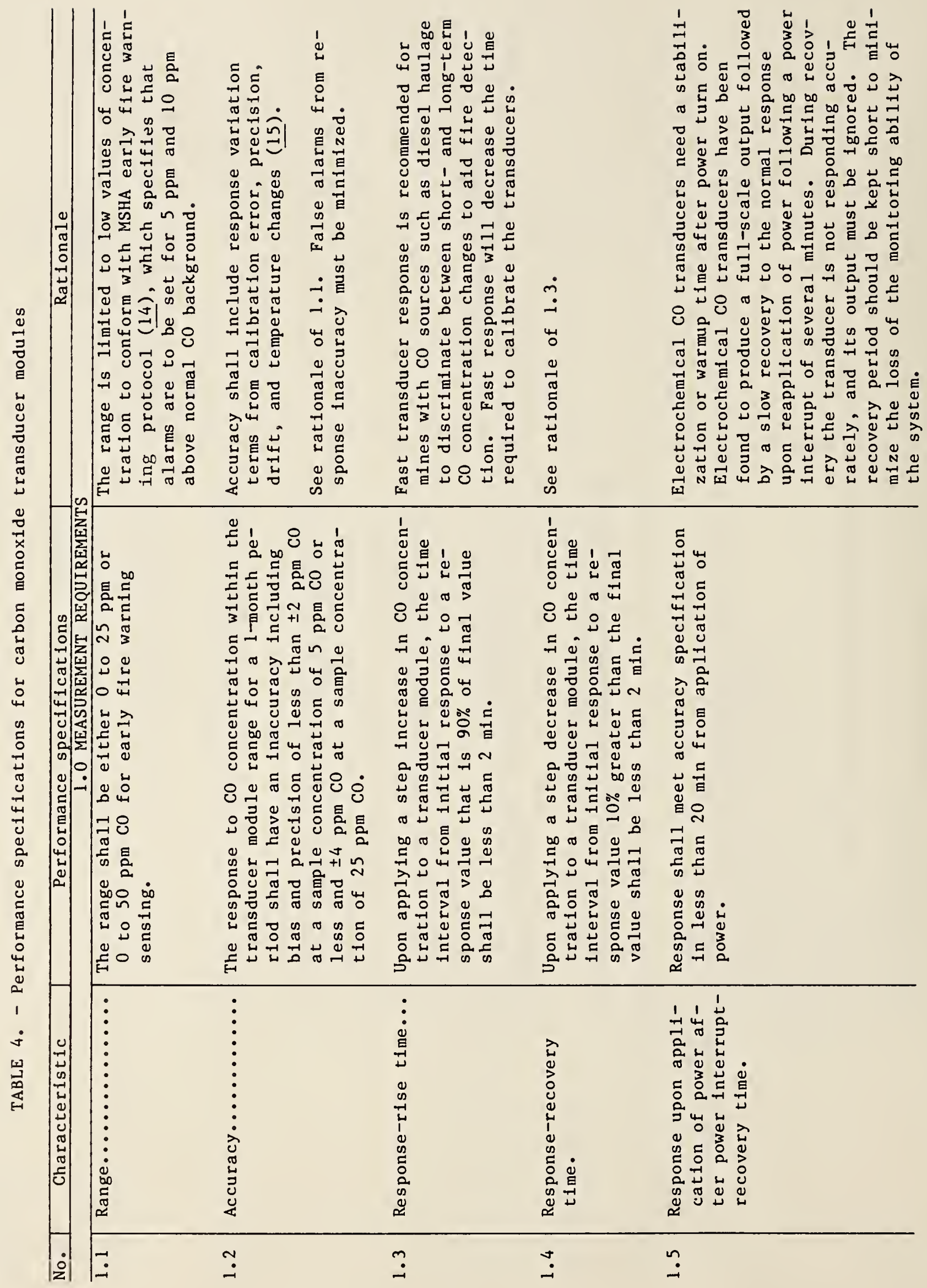




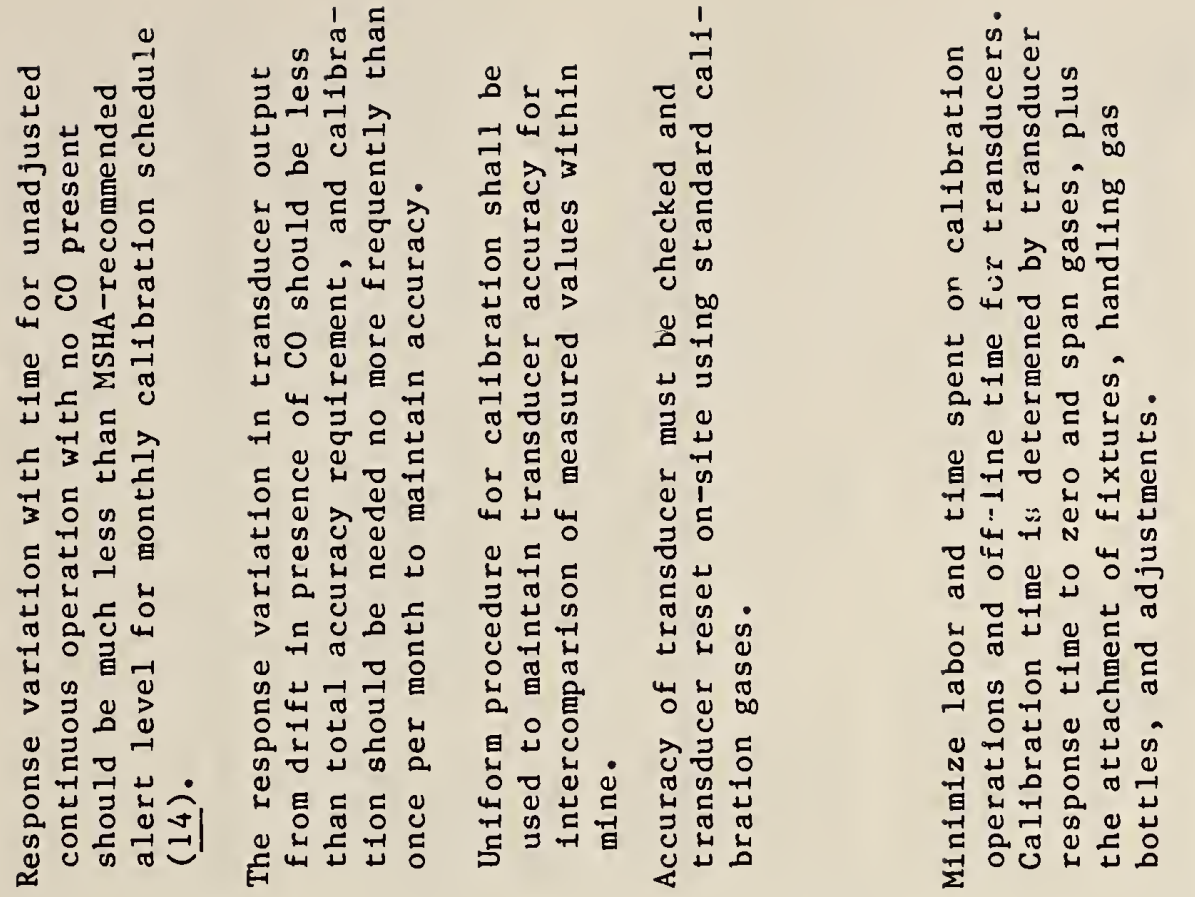

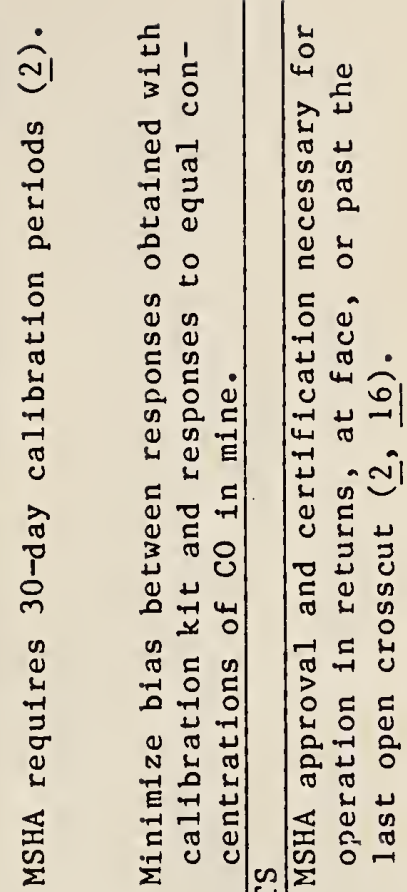

\begin{tabular}{|c|c|c|c|c|c|c|c|}
\hline 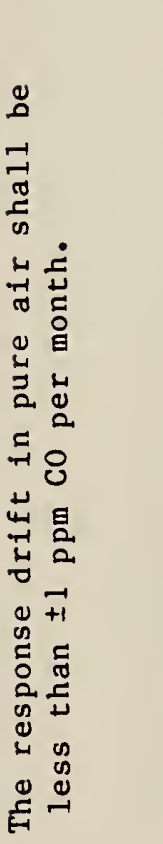 & 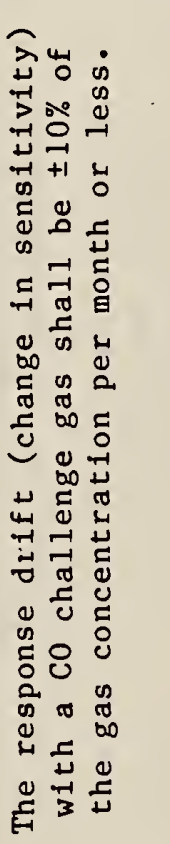 & 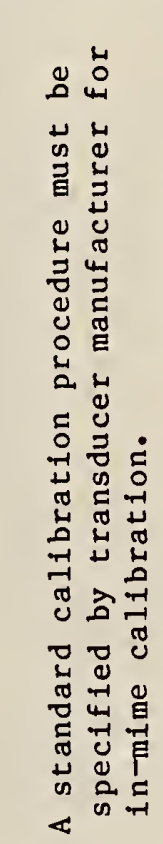 & 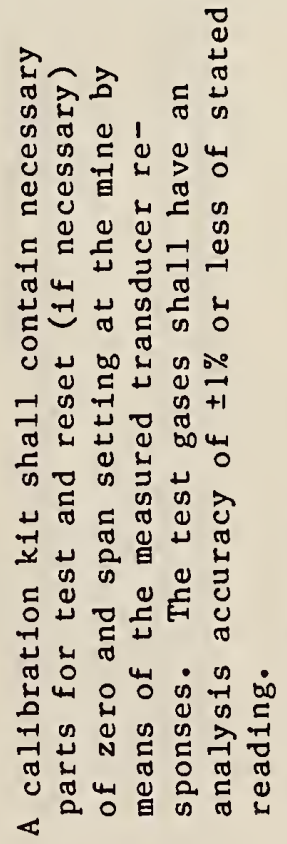 & 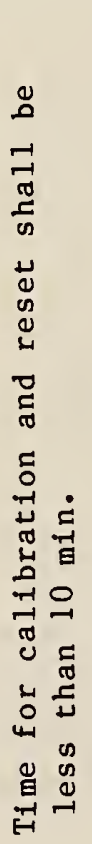 & 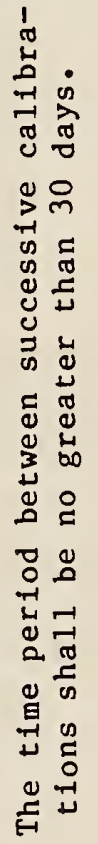 & 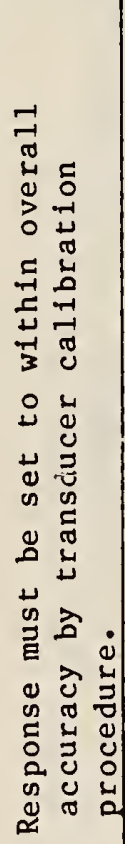 & 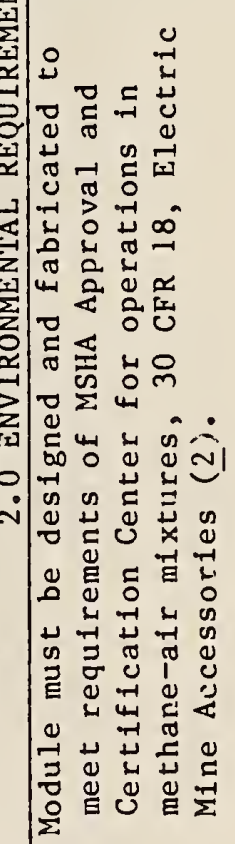 \\
\hline 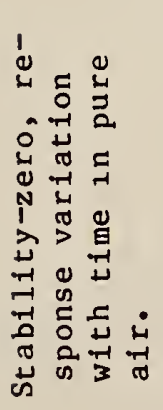 & 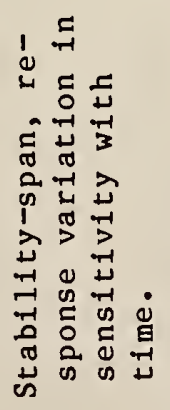 & 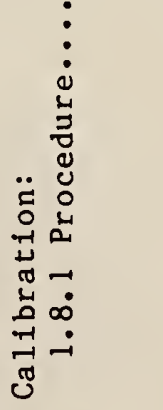 & 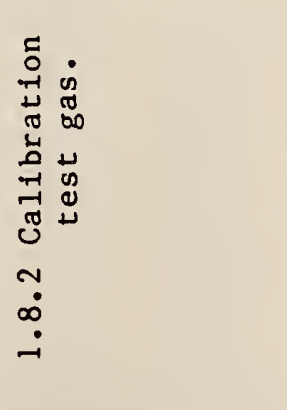 & 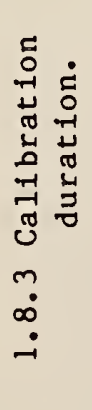 & 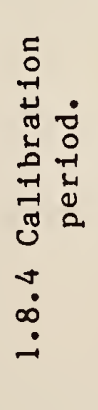 & 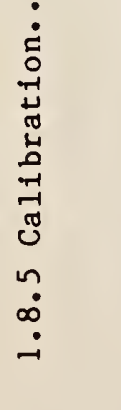 & 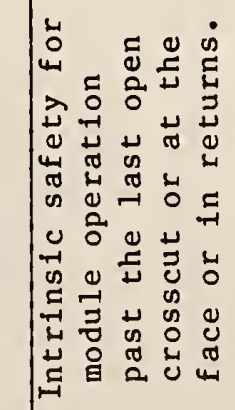 \\
\hline-1 & $\rightarrow$ & $\rightarrow$ & & & & & IN \\
\hline
\end{tabular}




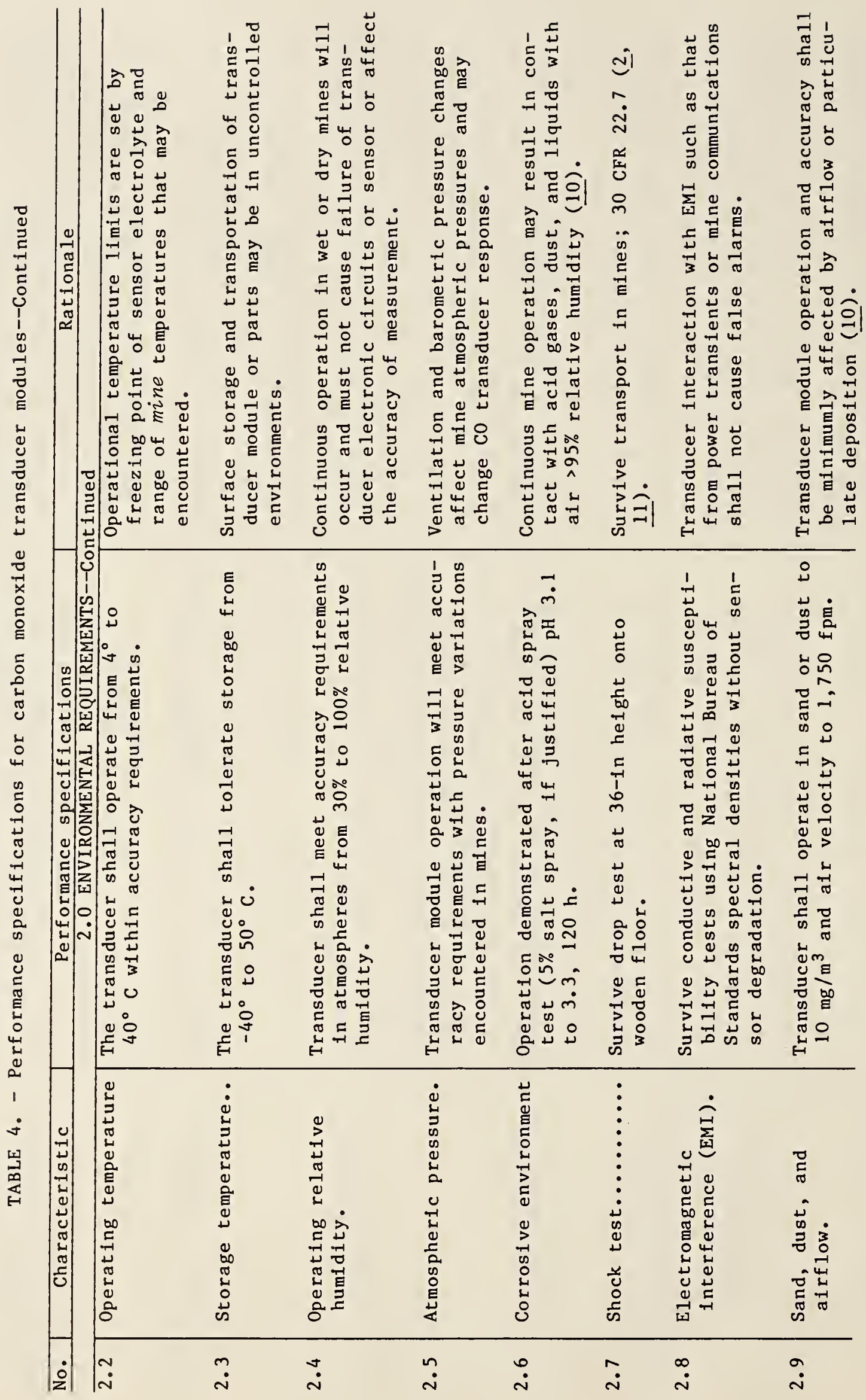




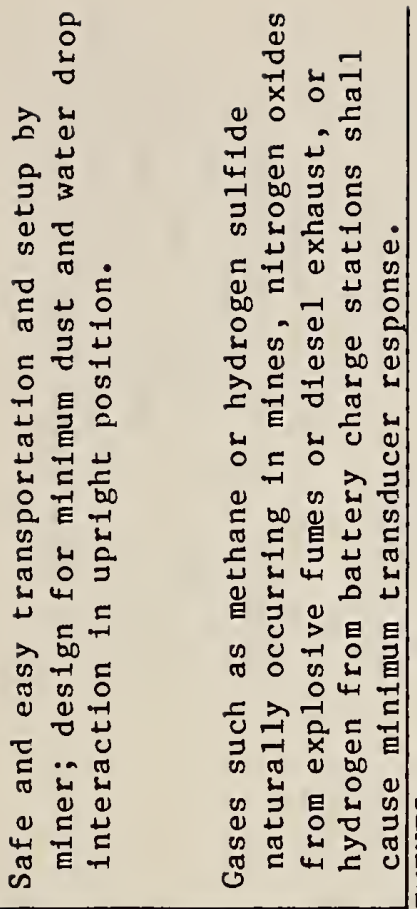

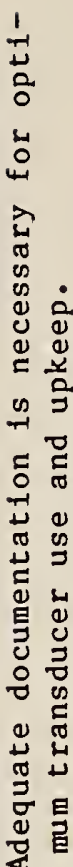

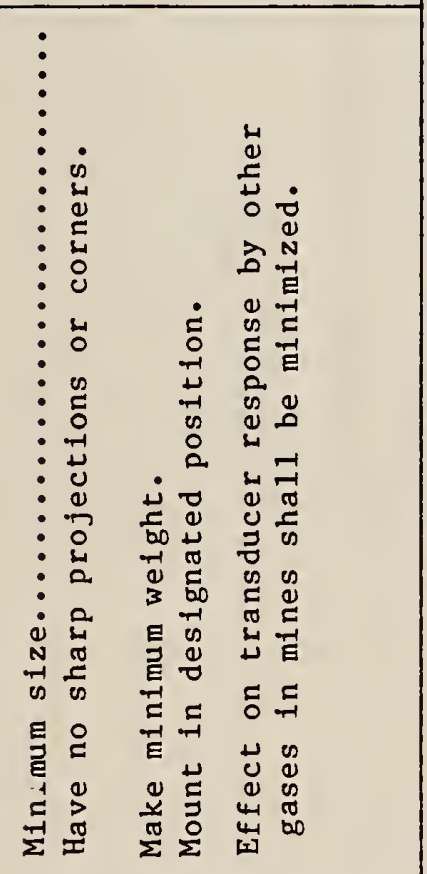

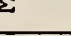

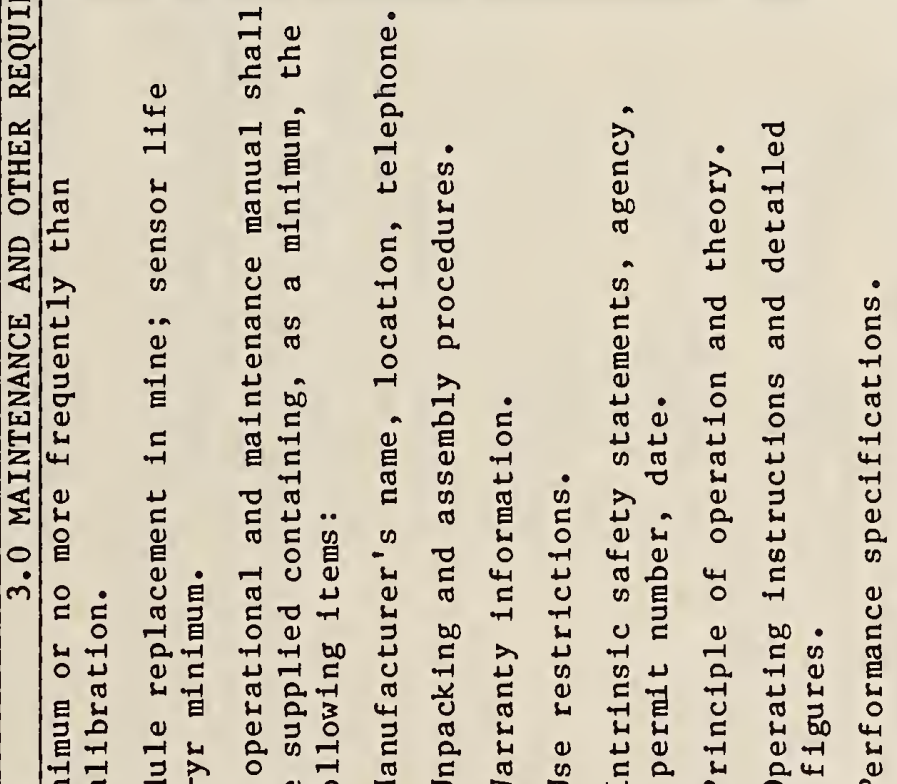

न न

एक

굴

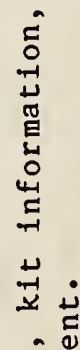

营

苛离出

嵌岕 岂

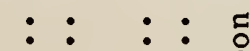

is: : : :

I $\vdots \vdots \vdots \vdots$ 吾

: $\vdots \vdots \vdots$

㟔: $\vdots \vdots \vdots$ :

$\Rightarrow:$ :

U व का

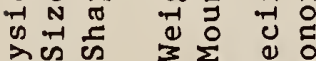

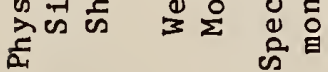

$\stackrel{ }{\dot{1}}$

$\ddot{\sim}$

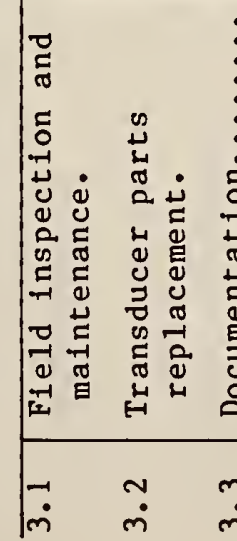




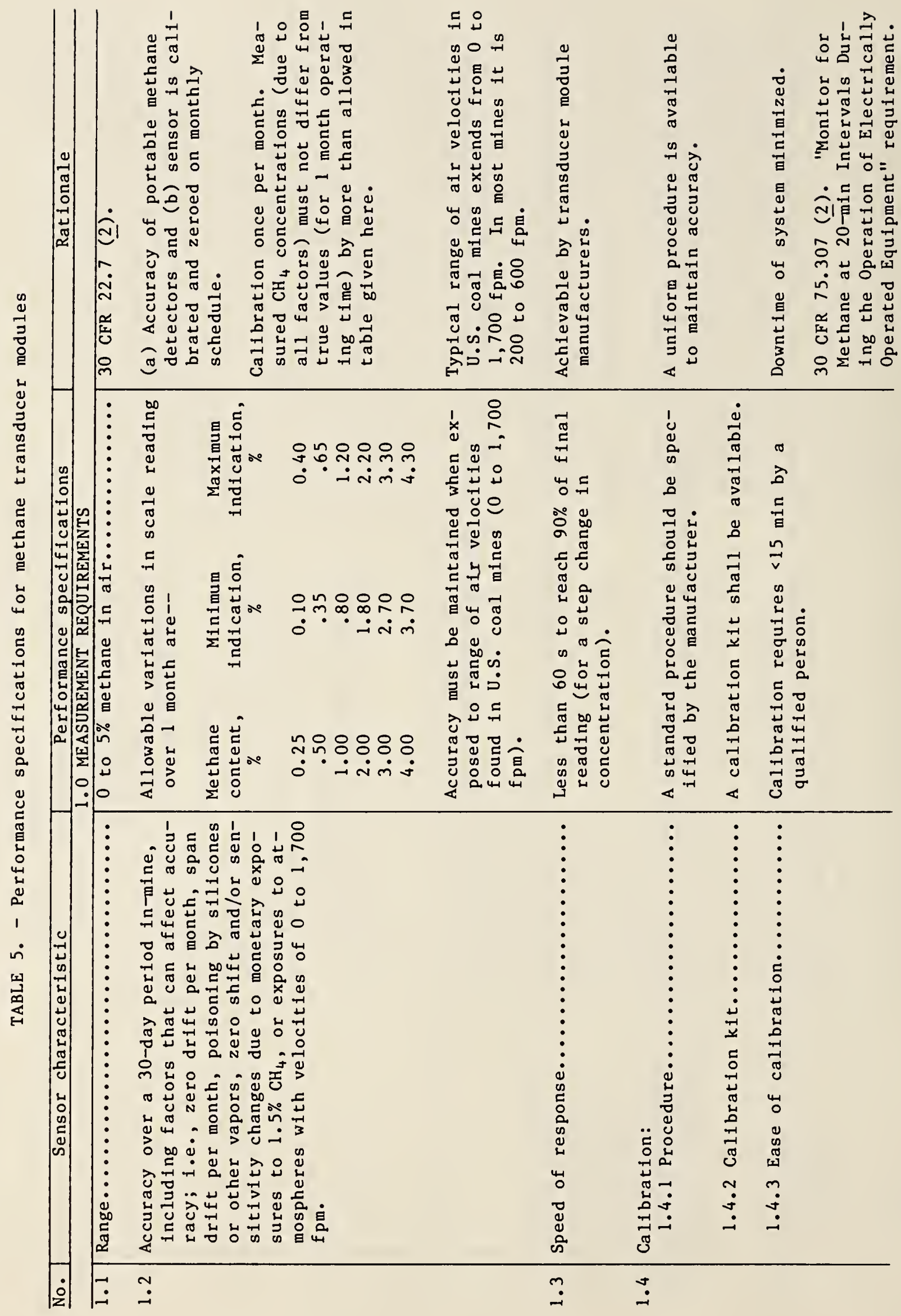




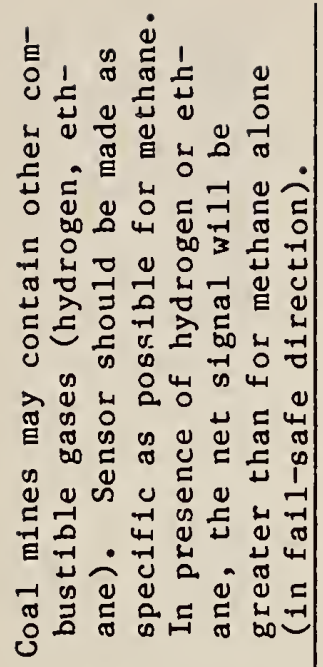

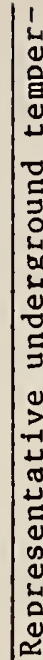

㻤完

퓨 흉

न 0 के

평

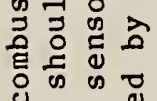

-1.. ע

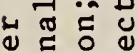

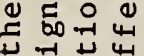

० कि ट्ष

㟧 节出

ه 궁

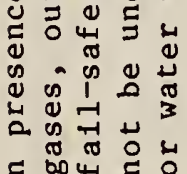

¿

กิ

$\dot{H}$

$\dot{\circ} \dot{\circ} \dot{\circ} \quad$ 㐘

离

్ㅏ

\begin{tabular}{|c|c|c|c|c|c|c|c|c|}
\hline 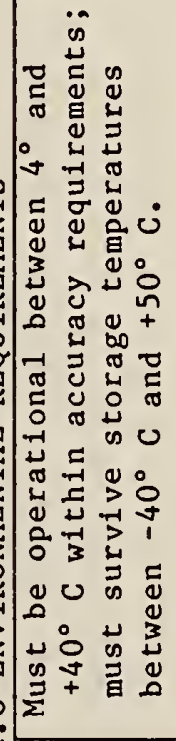 & 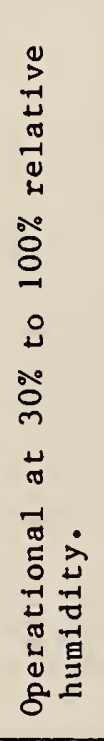 & 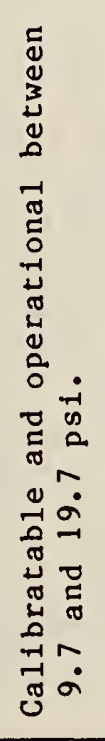 & 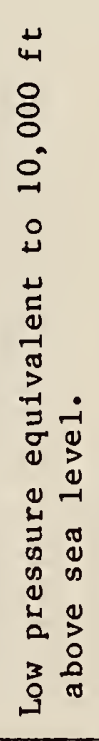 & 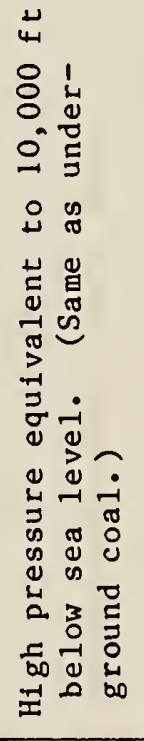 & 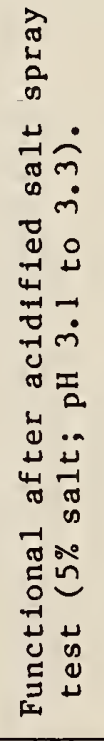 & 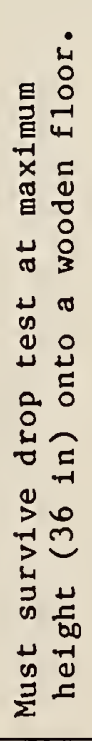 & 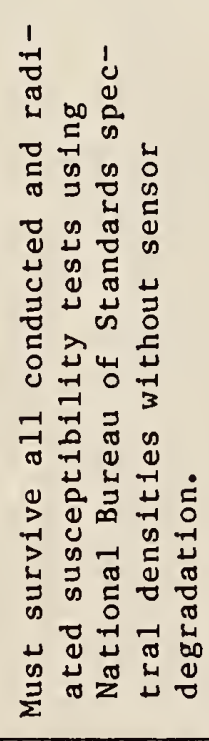 & 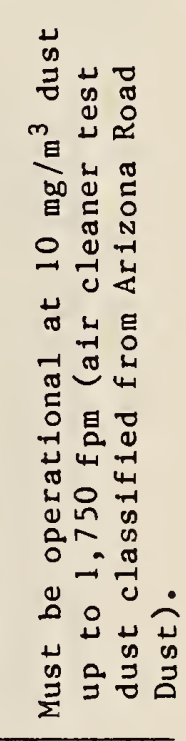 \\
\hline
\end{tabular}

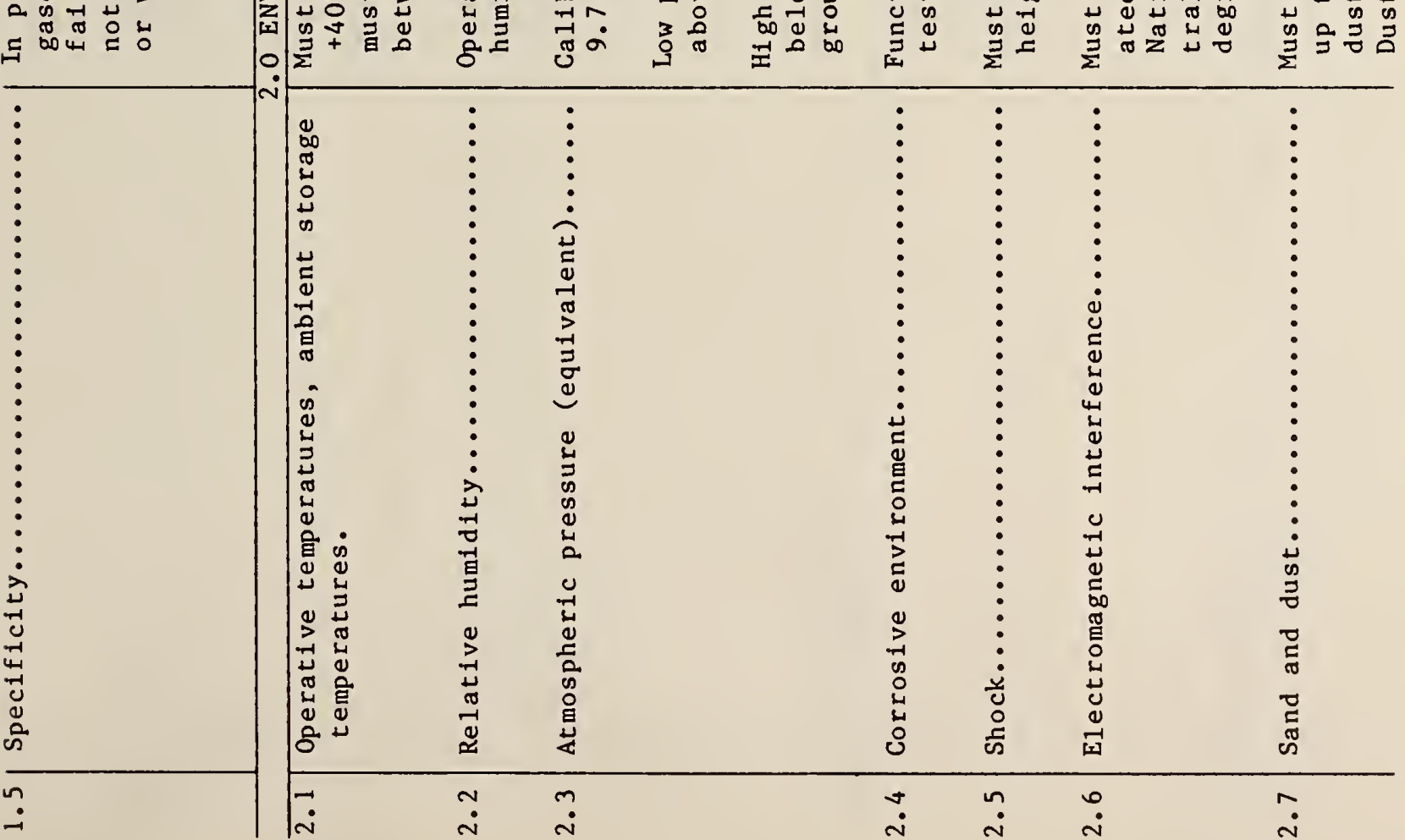




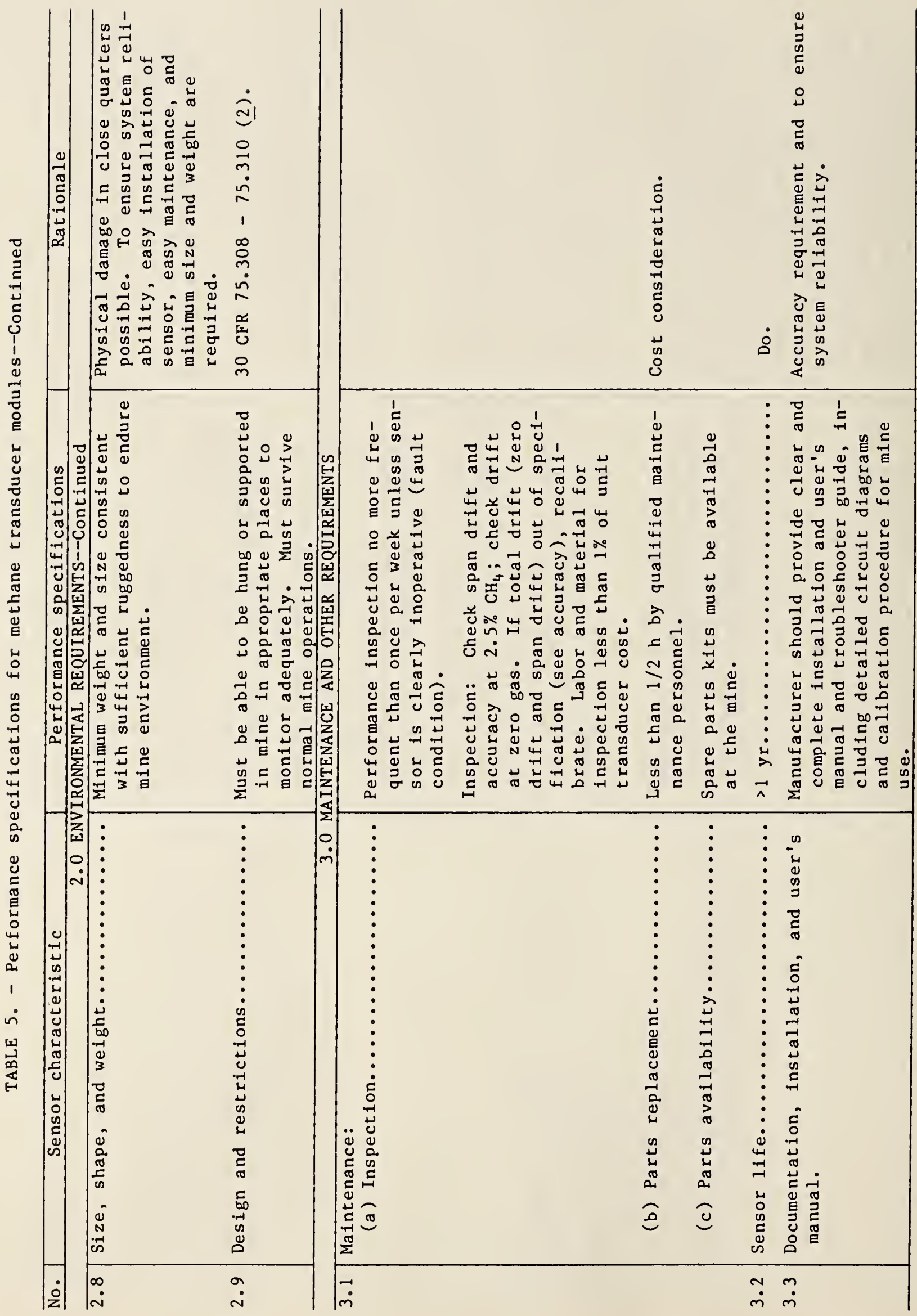




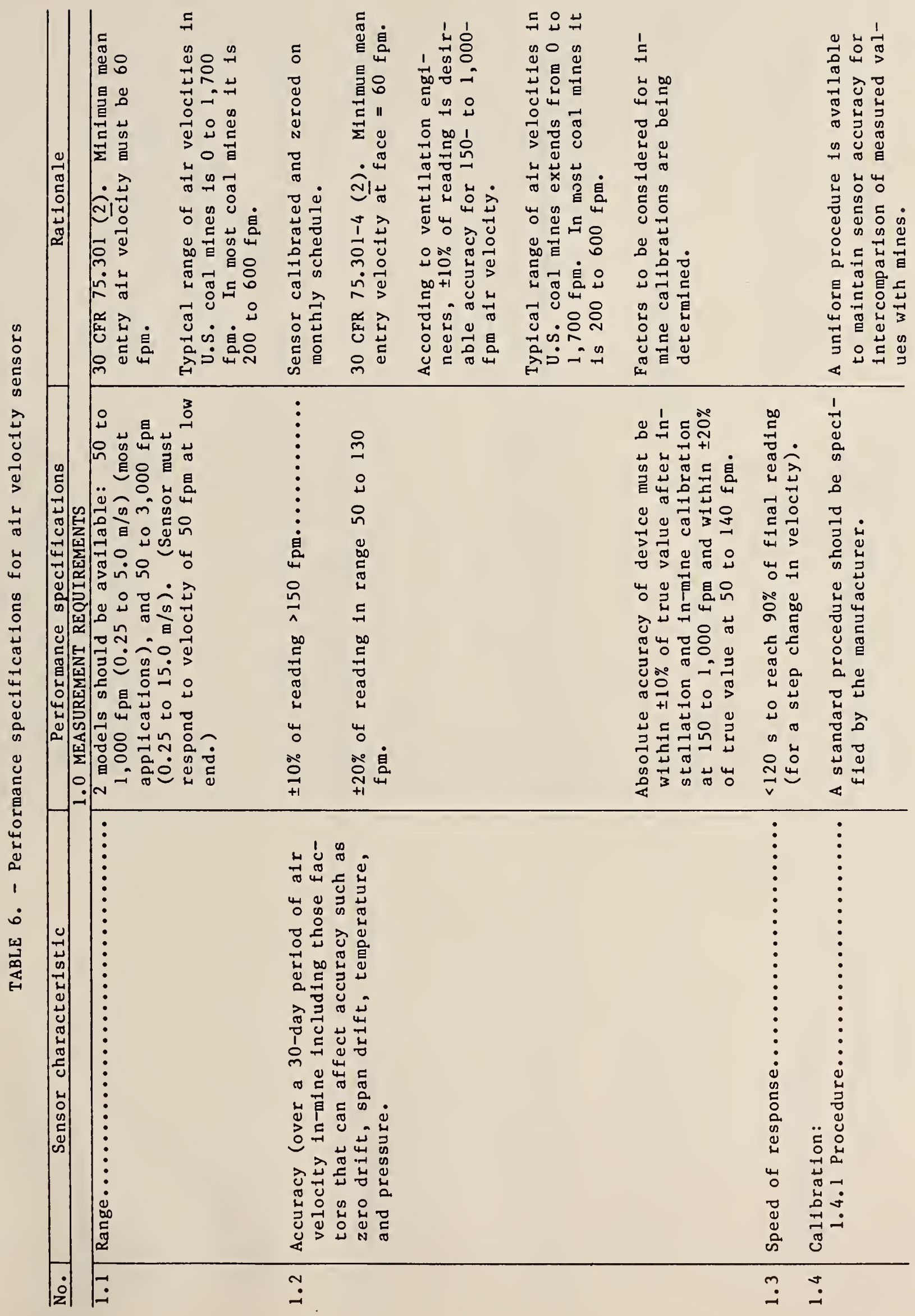




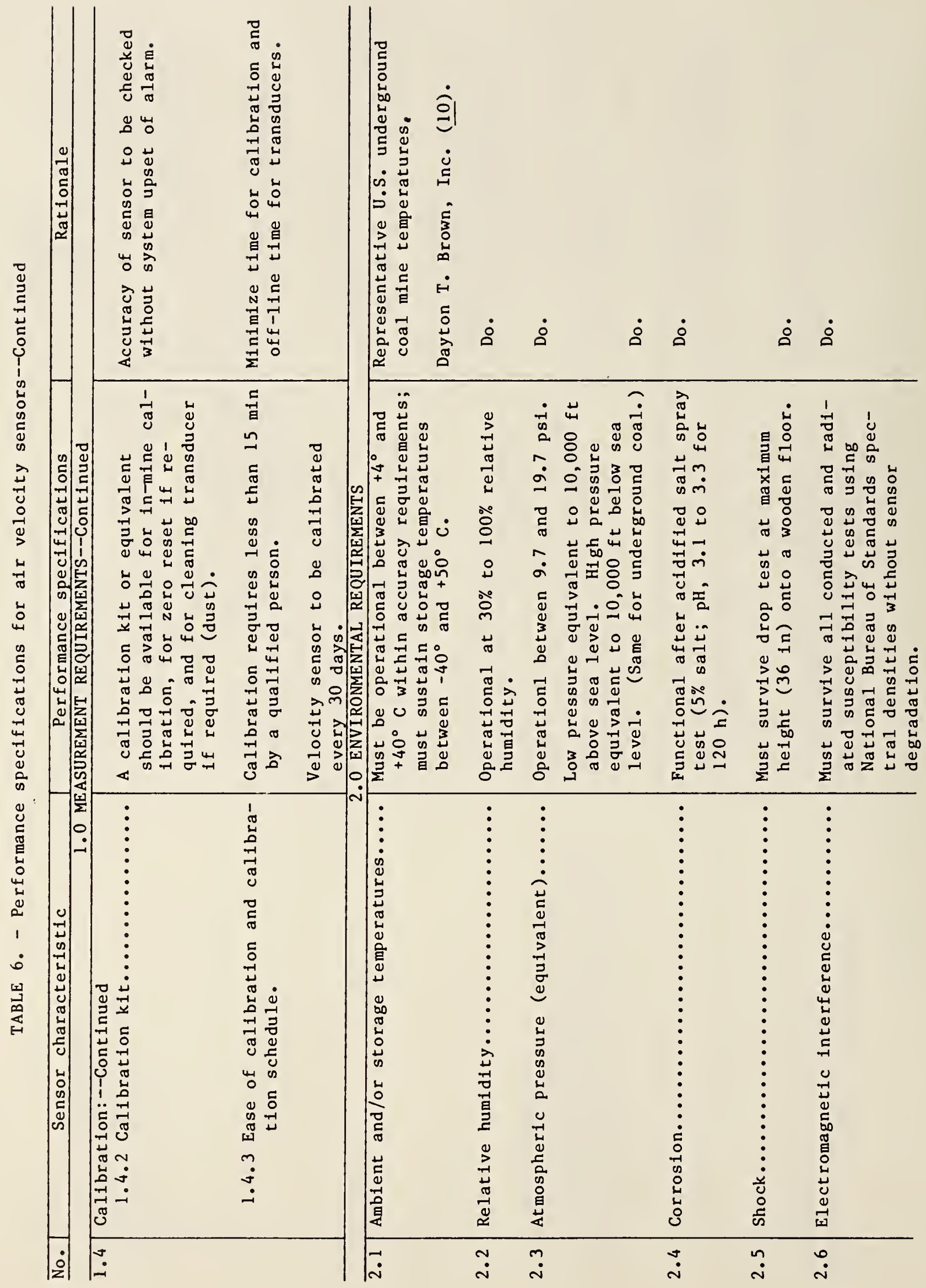




\begin{tabular}{|c|c|c|c|c|c|c|c|c|}
\hline 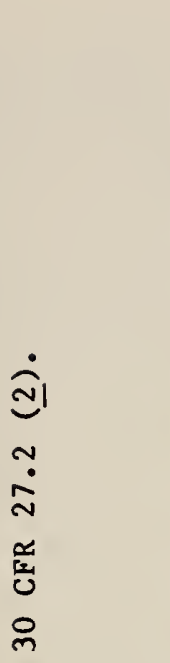 & 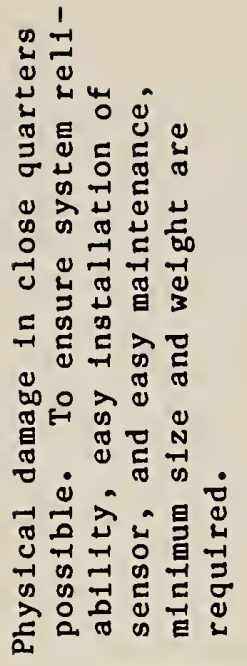 & 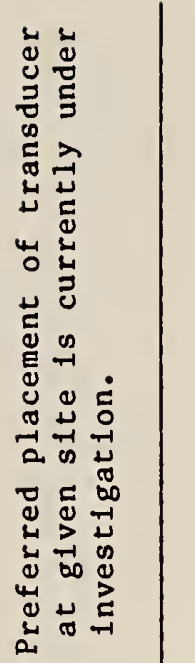 & 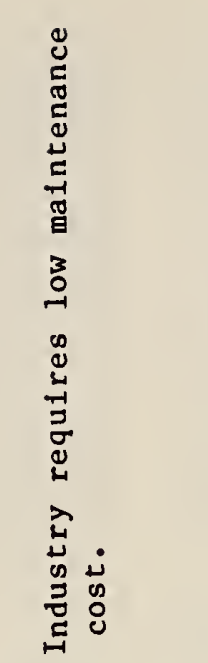 & 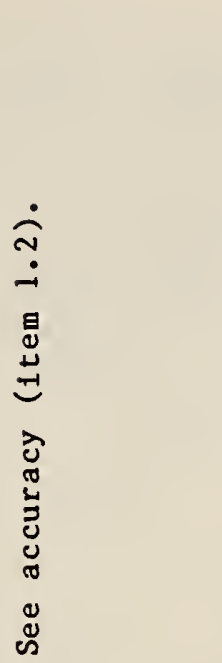 & & & 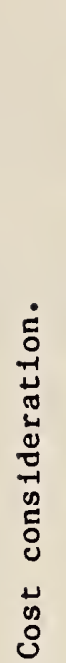 & 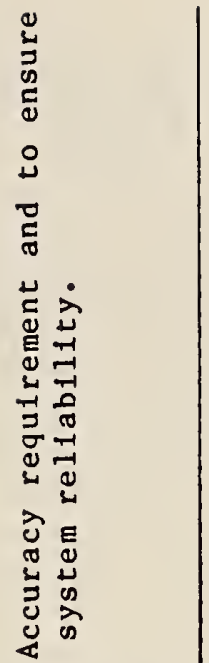 \\
\hline 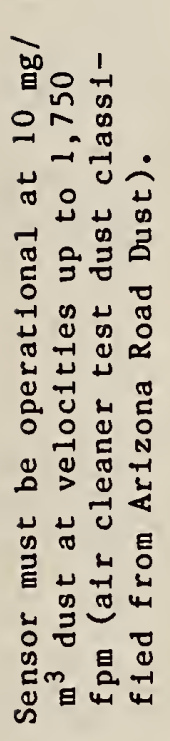 & 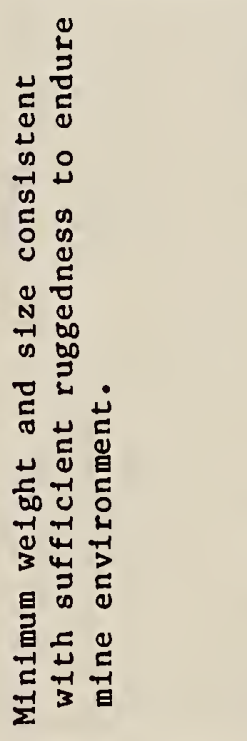 & 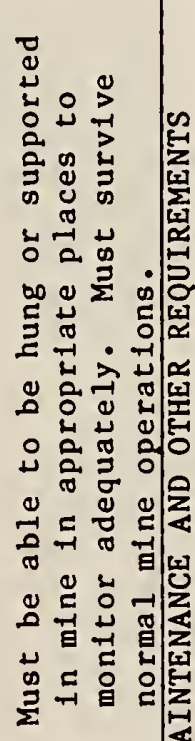 & 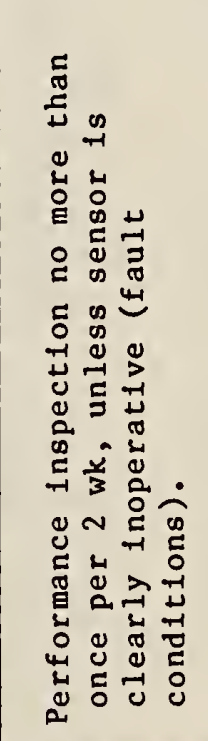 & 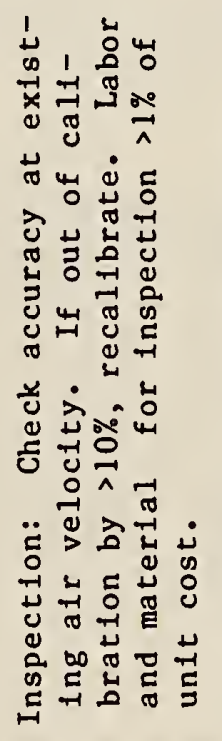 & 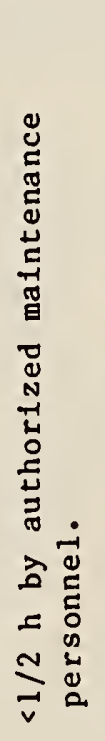 & 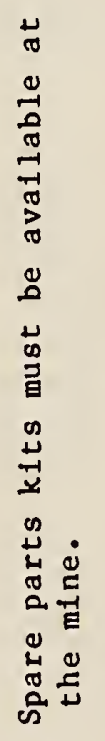 & 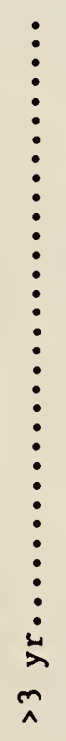 & 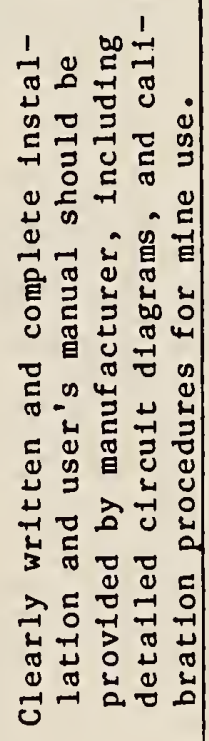 \\
\hline 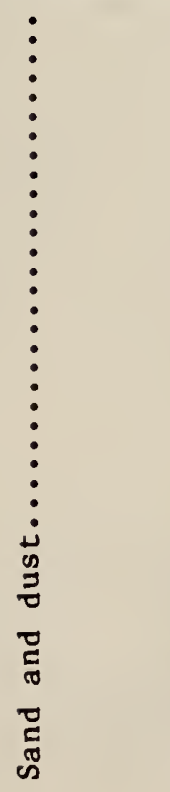 & 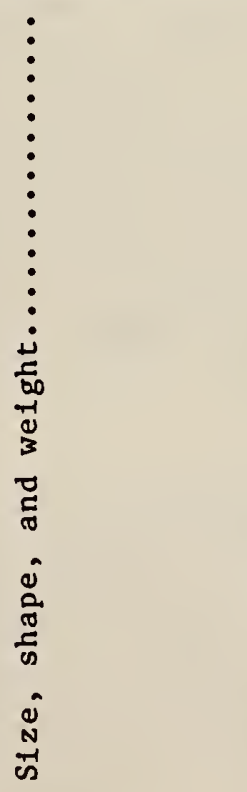 & 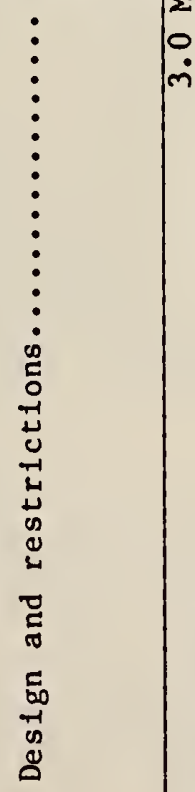 & 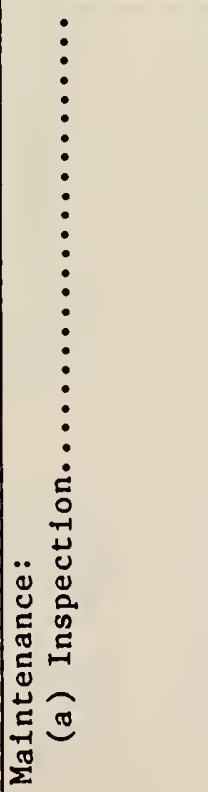 & & 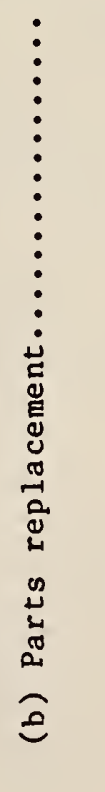 & 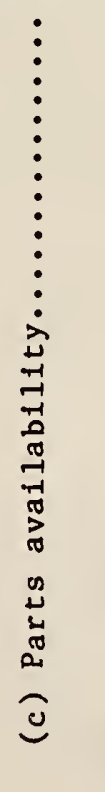 & 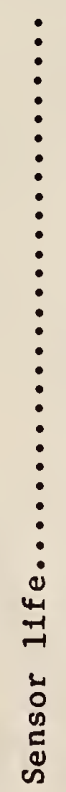 & 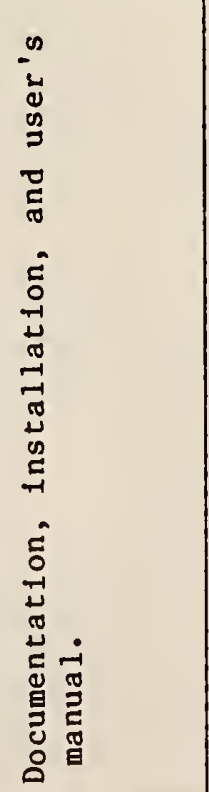 \\
\hline$\dot{\sim}$ & $\begin{array}{l}\infty \\
\dot{\sim}\end{array}$ & $\dot{\sim}$ & $\overrightarrow{\dot{m}}$ & & & & $\stackrel{\sim}{\sim}$ & $\dot{m}$ \\
\hline
\end{tabular}


For a monitoring system to be useful, it must accurately represent environmental conditions in a mine. Not only must the sensors function properly, but they must also be placed at strategic locations. If a mine had an unlimited budget for sensors, it could hang sensors everywhere, but this would then create maintenance problems. A mine must, therefore, optimize sensor placement for the particular intention of the application. Sensor placement must be considered not only on a minewide scale, but also on a local scale, such as the location within a particular cross section. Below are some general guidelines for sensor placement developed from in-mine sensor location strategy experiments (12-13, 17).

\section{Methane}

1. Placement of methane sensors should follow CFR requirements for handheld instruments. Appendix D gives the locations of examinations in 30 CFR Part 75.

2. Because methane comes from the coal itself, and because it is lighter than air, the highest concentrations are expected near the roof. The detector part of the sensor (catalytic bead) should be no closer than 12 in from roof or rib, as required in $30 \mathrm{CFR}$ Part 75.

\section{Carbon Monoxide}

1. For carbon monoxide sensors used for early fire detection, horizontal placement should be in the middle of the airway. Vertical placement should be close to but at least 4 in down from the roof.

2. Maximum spacing between sensors varies depending upon the application. Factory Mutual Research Corp., under
Bureau contract (18), has developed spacing guidelines for three scenarios: (1) beltway fire, (2) coal wall fire, and (3) wood wall fire. The spacing criteria also take into account ventilation rates, hazard time, and safety factor. For example, for a mine with a ventilation rate of $50 \mathrm{fpm}$ in a belt entry, an entry width of $18 \mathrm{ft}$, a seam height of $6 \mathrm{ft}$, and a safety factor of 0.5 (the safety factor ranges between 0 and 1 , with the larger the value, the more time available for response to the fire after detection), the recommended detector spacing would be $827 \mathrm{ft}$. Under the same conditions except with a ventilation rate of $100 \mathrm{fpm}$, the recommended spacing would be $1,462 \mathrm{ft}$. A further description of the procedure for determining carbon monoxide sensor spacing is contained in appendix E. Recommendations for carbon monoxide sensor spacing along the beltway as required by MSHA for a variance of 30 CFR 75.326 are contained in appendix $C$.

\section{Air Velocity}

1. Placement of air velocity sensors should follow CFR requirements for handheld instruments. Appendix $D$ gives the locations of examinations required in 30 CFR Part 75.

2. The geometric center of the airway cross section is the best place, preferably hung by suspension (e.g., guy wire).

3. Sensor placements at abrupt changes in the flow of air, such as at a bend, intersection, or obstruction, can cause sensors to indicate erroneous values. The influence of these abrupt changes in flow of air often extends 3 to 5 airway widths upstream and 10 or more widths downstream. These regions should be avoided.

\section{SUMMARY}

Computerized mine monitoring systems can provide a safer and more productive work environment for underground coal mines. Many mines are currently using them to provide miner safety, as evidenced by the number of mines that have placed carbon monoxide sensors along belt entries in order to use those entries as intake airways. In the future, as mines become deeper and more complex and as mining rates increase, environmental monitoring systems will play a greater role 
in providing mine safety. Even though mine monitoring can increase safety, this can only happen when both monitoring system manufacturers and mine operators keep safety in mind. Manufacturers must design systems for reliability and safety, and make sure these systems are installed properly and that the system operators are adequately trained in their operation before the manufacturer leaves the mine site. On the other hand, the mine operatcr must dedicate time and labor to the system in order to maintain it in good operating condition and provide the necessary people to operate it properly. Any failure on the part of the manufacturer or the mine operator can lead to serious consequences.

This report provides guidelines to the mining industry for the design, installation, and operation of environmental monitoring systems to provide miner safety. By following these guidelines, the potential for monitoring system failure can be reduced.

\section{REFERENCES}

1. Foose, H. E. System Evaluation and Barrier and Sensor Classification Under the Mine Safety and Health Administration Mine-Wide Monitoring System Program (Pres. at 14th Ann. Int. Symp. of the ISA, Mining and Metallurgy Division, Denver, CO, Apr. 29-May 2, 1986). Instrumentation in the Mining and Metallurgy Industry, v. 13, 1986, pp. 47-50.

2. U.S. Code of Federal Regulations. Title 30--Mineral Resources; Chapter I-Mine Safety and Health Administration, Department of Labor; Subchapters A-P, Parts 0 to 199. July 1, 1985, $732 \mathrm{pp}$.

3. Stricklin, K. G. Environmental Monitoring in Coal Mines. Paper in Proceedings of the 17 th Annual Institute on Coal Mining Health, Safety, and Research (Blacksburg, VA, Aug. 26-28, 1986). 1986, pp. 73-83.

4. U.S. Mine Safety and Health Administration. Preproposal Draft Rule To Revise Existing Safety Standards for Ventilation in Underground Coal Mines, 30 CFR Part 75. Nov. 1985; for further information, contact Patricia W. Silvey, Director, Office of Standards, Regulations, and Variances, MSHA, Arlington, VA (703) 235-1910.

5. Bureau of National Affairs, Inc. Technical Recommendations on Two-Entry Mining by MSHA Task Force on Longwall Mining. Mine Safety and Health Reporter, June 26, 1985, pp. 34-36.

6. Younglove, A., A. Pettinato, P. Macdiarmid, and S. Stagnitta. Reliability Analysis of U.S. Bureau of Mines Mine Monitoring Systems (contract
H0111838, Rome Air Development Center). BuMines OFR 33-83, 1983, 49 pp.

7. Nutter, R. S., N. S. Smith, W. R. Voltz, P. Klinkhachorn, and D. F. Tuthill. Methodology Development for Mine Life Safety System Evaluation (contract J0100057, WV Univ.). BuMines OFR 76-84, 1982, 428 pp.; NTIS PB 84-182765.

8. Bredeson, J. G., H. Hashemi, and K. Sneedhar. Data Security for In-Mine Transmission (contract J0308024, Univ. OK). BuMines OFR 88-84, 1982, 76 pp.; NTIS PB 84-185081.

9. Nutter, R. S., R. S. Chapman, A. M. Kissel, C. A. Winkelmann, and W. R. Voltz. Underground Mine Monitoring and Control Testing Criteria (contract J0113057, WV Univ.). BuMines OFR 51-85, 1984, 155 pp.; NTIS PB 85-228864.

10. Trelewicz, K. Environmental Test Criteria for the Acceptability of Mine Instrumentation (contract J0100040, Dayton T. Brown, Inc.). BuMines OFR 1-82, 1981, 137 pp.; NTIS PB 82-146335.

11. Fisher, T. J., and M. Uhler. Research To Develop an Intrinsically Safe Monitoring System for Coal Mines. Paper in Proceedings of the Fifth WVU Conference on Coal Mine Electrotechnology, July 30, 31, August 1, 1980 (contract J0100049, WV Univ•). BuMines OFR 82-81, 1980, pp. 20-1 to 20-10.

12. Cohen, A. F. Choosing Fixed-Point Mine Monitoring Air Velocity Sensor Sites (In-Mine Experiments) (Pres. at 14th Ann. Int. Symp. of the ISA, Mining and Metallurgy Division, Denver, Co, April 29-May 2, 1986). Instrumentation in the 
Mining and Metallurgy Industry, v. 13, 1986, pp. 19-36.

13. Cohen, A. F., T. J. Fisher, R. A. Watson, and J. L. Kohler. Location Strategy for Methane, Air Velocity, and Carbon Monoxide Fixed-Point Mine Monitoring Transducers. Paper in Proceedings of the $7 \mathrm{th}$ WVU Mining Electrotechnology Conference (Morgantown, WV, July 24-27, 1984). WV Univ., 1984, pp. 180-193.

14. Miller, E. J., P. M. Turcic, and J. L. Banfield. Equivalency Tests of Fire Detection Systems for Underground Coal Mines Using Low Level Carbon Monoxide Monitors. Paper in Proceedings 2nd International Mine Ventilation Congress (Reno, NV, Nov. 4-8, 1979), AIME, 1980, Pp. 27-1 to 27-8.
15. American Society for Testing and Materials. Standard Specifications for Carbon Monoxide in the Atmosphere, D-11 Committee, Sampling and Analysis of Atmospheres. Philadelphia, PA, 1978, 4 pp.

16. National Fire Protection Association. Intrinsically Safe Apparatus for Use in Division 1 Hazardous Locations. NFPA Bu11. 493, 1978, 55 pp.

17. Litton, C. D. Guidelines for Siting Product-of-Combustion Fire Sensors in Underground Mines. BuMines IC 8919, 1983, 13 pp.

18. Newman, J. S., and M. M. Khan. Standard Test Criteria for Evaluation of Underground Fire Detection Systems-Final Report (contract H0113017, Factory Mutual Research Corp.). BuMines OFR 54-85, 1984, 217 pP.; NTIS PB 85-204170. 


\section{APPENDIX A.--SENSING TECHNIQUES OF ENVIRONMENTAL SENSORS}

A number of commercially available environmental sensors are suitable for use with computerized monitoring systems. During the last $10 \mathrm{yr}$, improvements in circuit design and construction have resulted in sensors that can be used in the mine environment. In selecting a sensor, attention should be paid to its reliability and the specificity and accuracy of the reading. In this appendix, the measurement techniques for carbon monoxide, methane, and air velocity sensors are discussed.

\section{METHANE SENSORS}

There are two primary techniques for detecting and measuring methane concentration that are suitable for mine monitoring use: Heat of combustion and infrared absorption. Heat-of-combustion or catalytic combustion sensors are the most common in the United States. These sensors detect the presence and concentration of methane by measuring the temperature rise of a catalytic element that oxidizes the methane at very low temperatures without a flame. The temperature rise in the catalyst is proportional to the methane content of the air surrounding the sensor.

There is some difference in the technique by which the sensors expose the catalyst to the gas mixture to be measured. Some devices rely on diffusion of the gas mixture through a porous metal flame arrestor screen. These are called diffusion-head type sensors. Others use mechanical pumps to draw air samples across the catalyst. Another method alternately draws the sample in and then exhales prior to the next sample. While the diffusion devices have a slower response time, they are simpler and do not rely on mechanical pumps that may be affected by dust and moisture. Although catalytic combustion sensors are relatively rugged and simple in operation, they have a disadvantage in terms of specificity. The catalyst temperature will rise in the presence of any combustion gas, not just methane. This is not always a problem, and can be reduced by operating at a specified temperature or selecting a catalyst that favors a methane-oriented chemical reaction. Another disadvantage is that catalytic sensors are not generally suitable for measuring methane concentrations above $5 \%$.

The second methane-sensing technique is based on the absorption by different gases of different amounts of infrared radiation. Typically, infrared energy is passed through a sample cell that has windows that do not absorb in the infrared band. The sensor is either equipped with a reference cell or calibrated by purging the sample cell with nitrogen prior to making measurements. An infrared detector located on the opposite side of the cell produces an electrical signal proportional to the difference between the reference and the sample, which is proportional to the methane concentration. Infrared sensors can be used to measure methane concentrations in the entire range between $0 \%$ and $100 \%$. While infrared sensors are relatively sensitive and specific, they are typically more complex and expensive than catalytic sensors.

\section{AIR VELOCITY SENSORS}

Two types of air velocity sensors are applicable to underground mining, rotating-vane anemometers and acoustic vortexshedding anemometers.

Rotating-vane anemometers are mechanical devices with vanes or impellars that are rotated or turned by the air flowing through the anemometer. The better instruments use ball bearings that reduce the turning friction of the main shaft on which the vanes are mounted to improve the accuracy at low air velocities. While this device is simple in operation, its susceptibility to excessive dirt and moisture is a disadvantage.

The second type of anemometer, acoustic vortex shedding, measures air velocity by sensing the frequency at which vortices'are shed from a rod placed in the 
airstream. The vortices in the airstream are sensed by the effect they have on an acoustic (ultrasonic) pulse transmitted through them. Since vortex-shedding anemometers have no moving parts, they are well suited for underground mines.. They are also typically more expensive than mechanical anemometers.

\section{CARBON MONOXIDE SENSORS}

Carbon monoxide is produced by the thermal oxidation of materials containing carbon. For wood or coal, carbon monoxide is the major gas evolved at $50^{\circ}$ to $150^{\circ} \mathrm{C}$. The presence of carbon monoxide in the mine atmosphere can be used as a warning of incipient fire. Since carbon monoxide is also produced from diesel exhaust or explosive products (shot firing), if gases from these products come in contact with carbon monoxide sensors, the sensor also reacts. Therefore, the warning system must be able to differentiate the source of the carbon monoxide.

Most carbon monoxide sensors used in this country are the electrochemical amperometric type, in which carbon monoxide is electrocatalytically oxidized to form carbon dioxide. From this oxidation process a current is produced that is proportional to the carbon monoxide concentration. The air to be sampled either is allowed to diffuse into the sensor or is drawn in by a mechanical pump. This type of sensor is stable, lasting up to $2 \mathrm{yr}$ in a mine environment, is inexpensive (original cost of the sensor is under $\$ 100)$, and is sensitive to low concentrations of carbon monoxide ( $10 \mathrm{ppm})$. Other gases that are electrochemically oxidizable will also produce a current at the electrode, acting as if they were carbon monoxide. They include hydrogen, acetylene, ethylene, nitric oxide, nitrogen dioxide, hydrogen sulfide, and sulfur dioxide. Gas-interferent filters may be used with the sensor to remove the active hydrocarbons, nitrogen, and sulfur gases, but these filters must be replaced regularly to be effective.

There are other techniques for measuring carbon monoxide at the 10-ppm concentration at fixed locations. In one, carbon monoxide is measured from the heat produced by catalytic oxidation over a Hopcalite catalyst. The resulting temperature rise in the catalyst is proportional to the gas concentration. Here, the basic technique is nonspecific, and carbon monoxide-specific catalysts and appropriate filament temperatures are required to reduce the interference of other combustible gases.

Another technique is absorption of infrared energy. This is similar to that described for methane detection. The sensor is made selective for carbon monoxide by modifying the methane receiver transducer to detect changes in the infrared wavelengths that are absorbed by carbon monoxide molecules. For nondispersive systems, the absorption filters must be changed, and for dispersive systems, the refraction grating must be changed.

Carbon monoxide may also be measured by the conductivity change in metal-oxide semiconductor sensors, such as tin oxide and zinc oxide solid state sensors. These solid state sensors are sensitive to a large number of gases and are used in British coal mines for monitoring total fire products.

Figure $A-1$ is a diagram of the carbon monoxide transducer module. 


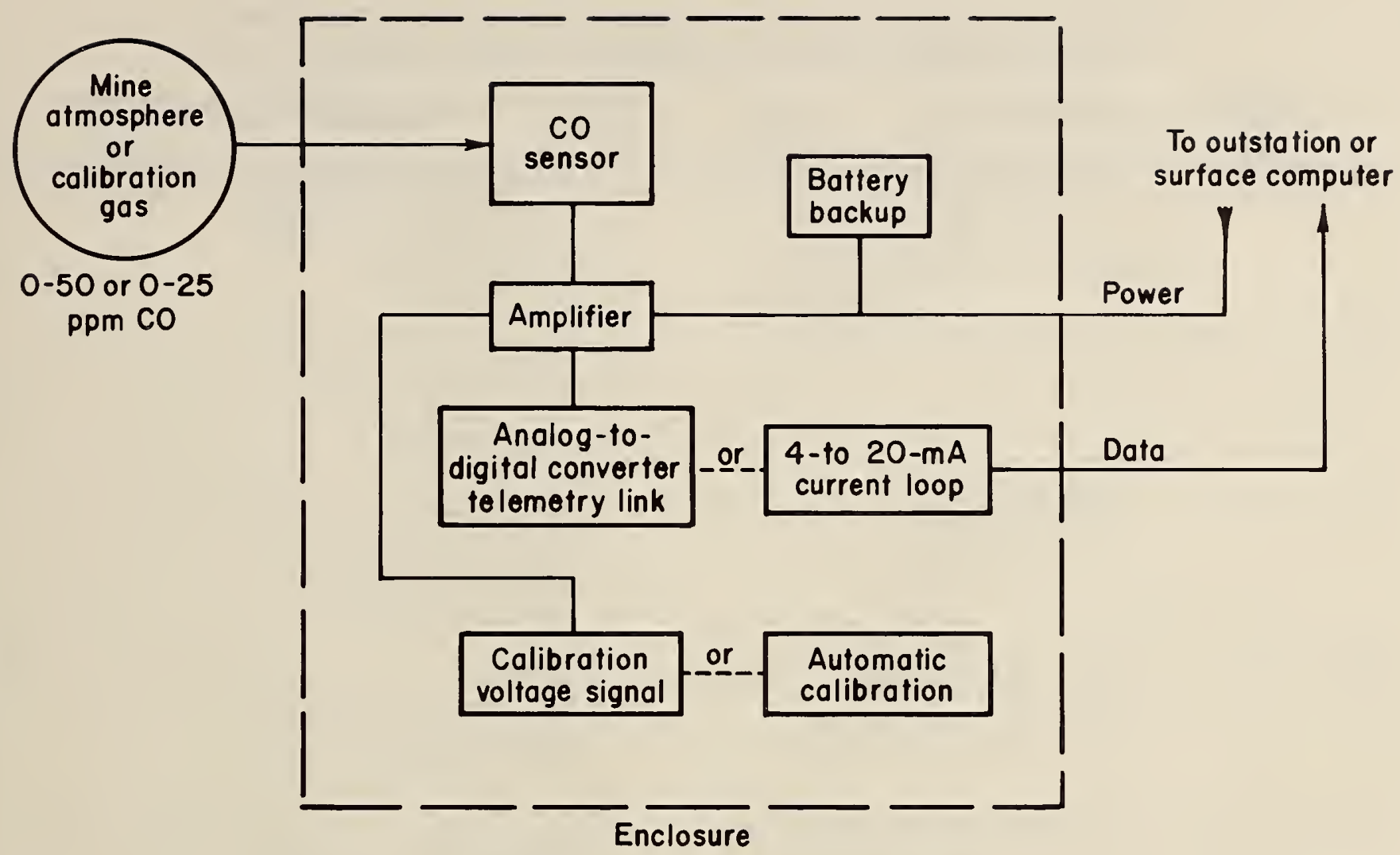

FIGURE A-1.-Carbon monoxide transducer module. 
APPENDIX B.--MANUFACTURERS OF MONITORING SYSTEMS EVALUATED UNDER THE MSHA MINEWIDE MONITORING SYSTEM PROGRAM

\begin{tabular}{|c|c|c|c|}
\hline $\begin{array}{c}\text { MSHA } \\
\text { evaluation }\end{array}$ & Date & Mode 1 & Company and address \\
\hline$\overline{M M S-1-0 \ldots \ldots \ldots}$ & $11 / 24 / 82$ & M/C 8000 Series..... & $\begin{array}{l}\text { Transmitton Inc. } \\
1101 \text { Parkway View Dr. } \\
\text { Pittsburgh, PA } 15205 \\
\text { (412) } 787-3383\end{array}$ \\
\hline MMS $-2-0 \ldots \ldots \ldots$ & $03 / 02 / 83$ & $2002 \ldots \ldots \ldots \ldots$ & $\begin{array}{l}\text { Giangarlo Scientific } \\
2500 \text { Baldwick Rd. } \\
\text { Pittsburgh, PA } 15205 \\
\text { (412) } 922-8850\end{array}$ \\
\hline MMS $-3-0 . \ldots \ldots$ & $07 / 22 / 83$ & MUN-354.......... & $\begin{array}{l}\text { Mund1x Control Systems, Inc. } \\
5495 \text { Marion St. } \\
\text { Denver, C0 } 80216 \\
\text { (303) 296-1790 }\end{array}$ \\
\hline MMS-4-0...... & $09 / 15 / 83$ & Senturion $200 \ldots \ldots$.... & $\begin{array}{l}\text { Conspec, Inc. } \\
1701 \text { McFarland Rd. } \\
\text { Pittsburgh, PA } 15216 \\
(412) 563-6060\end{array}$ \\
\hline MMS-5-0...... & $10 / 03 / 83$ & DGS-1000/430....... & $\begin{array}{l}\text { Appalachian Electronic Inst., Inc. } \\
810 \text { West Monroe Ave. } \\
\text { Ronceverte, WV } 24970 \\
\text { (304) 647-5855 }\end{array}$ \\
\hline MMS $-6-0 . \ldots \ldots$ & $01 / 26 / 84$ & KDS ............ & $\begin{array}{l}\text { Kidde Automated Systems, Inc. } \\
725 \text { G County Line Road } \\
\text { Deerfield, IL } 60015 \\
\text { (312) } 272-8012\end{array}$ \\
\hline MMS-7-0...... & $03 / 13 / 84$ & 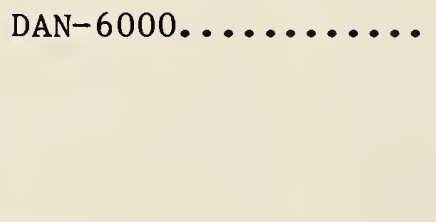 & $\begin{array}{l}\text { Mine Safety Appliances Co. } \\
\text { Instrument Div. } \\
\text { P.0. Box } 427 \\
\text { Pittsburgh, PA } 15230 \\
\text { (412) } 776-8600\end{array}$ \\
\hline MMS-7-1...... & $12 / 19 / 84$ & $\mathrm{DAN}-6000 \ldots \ldots \ldots$ & Do. \\
\hline
\end{tabular}


APPENDIX B.--MANUFACTURERS OF MONITORING SYSTEMS EVALUATED UNDER THE MSHA MINEWIDE MONITORING SYSTEM PROGRAM--Continued

\begin{tabular}{|c|c|c|c|}
\hline $\begin{array}{c}\text { MSHA } \\
\text { evaluation }\end{array}$ & Date & Model & Company and address \\
\hline MMS $-8-0 \ldots \ldots \ldots$ & $05 / 02 / 84$ & DYNALINK........... & $\begin{array}{l}\text { Hawker-Siddeley Dynamics Engineering } \\
\text { Bridge Road East } \\
\text { Welwyn Garden City } \\
\text { Hertfordshire England } \\
\text { AL7 lLR } \\
\text { Welwyn Garden (07073) } 31299 \\
\qquad \text { OR } \\
\text { Ohio Brass Co. } \\
\text { (U.S. representatives) } \\
380 \text { North Main St. } \\
\text { Mansfield, OH } 44903 \\
\text { (419) 522-7111 }\end{array}$ \\
\hline MMS $-9-0 . \ldots \ldots$ & $09 / 06 / 84$ & $845901 \ldots \ldots \ldots \ldots$ & $\begin{array}{l}\text { Femco Div., Gulton Industries } \\
\text { P.0. Box } 33 \\
2000 \text { Bethel Dr. } \\
\text { High Point, NC } 27261 \\
\text { (919) } 887-2611 \\
\text { National Mine Service } \\
\text { (sales) } \\
600 \text { North Bell Ave. } \\
\text { Bldg. 2, Suite } 110 \\
\text { Carnegie, PA } 15106 \\
\text { (412) 429-0800 }\end{array}$ \\
\hline MMS $-9-1 \ldots \ldots \ldots$ & $12 / 03 / 84$ & $845901 \ldots \ldots \ldots \ldots$ & $\begin{array}{l}\text { Femco Div., Gulton Industries } \\
\text { (Address given above.) }\end{array}$ \\
\hline MMS $-12-0 . \ldots \ldots$ & & EZ-1000 Series...... & $\begin{array}{l}\text { Rel Tek Corp. } \\
616 \text { Beatty Rd. } \\
\text { Monroeville, PA } 15146 \\
(412) 373-6700\end{array}$ \\
\hline
\end{tabular}




\section{APPENDIX C.--CONDITIONS FOR PETITIONING FOR MODIFICATION OF APPLICATION OF 30 CFR 75.326}

This section contains conditions that must be met by a mine operator considering a $101 \mathrm{C}$ petition of 30 CFR 75.326-Aircourse and Belt Haulage Entries, to use the belt haulage entry as an intake aircourse. They have been set by MSHA, but all variances are granted on a caseby-case basis, and meeting the following criteria does not automatically qualify the use of the belt entry as an intake aircourse.

1. A fire detection system shall be installed as follows:

(a) Low-level CO monitoring devices shall be installed in all belt entries utilized as intake aircourses.

(b) The Co-monitoring devices shall be located so that the air is monitored at each belt drive, tailpiece, and other locations as may be required by the MSHA District Manager to insure the safety of miners.

(c) The co monitoring devices shall be capable of giving a warning automatically when the level of $\mathrm{CO}$ of any $10^{-}$ cation specified above exceeds $5 \mathrm{ppm}$ above the ambient level of the mine.

(d) The Co monitoring devices shall be capable of providing both visual and audible alarm signals.

(e) The monitoring system shall have the capability of identifying any activated sensor within the belt haulage entry. This system shall also have a map or schematic which will identify all monitor and flight locations.

(f) The monitoring devices shall initiate fire alarm signals at a manned location on the surface where personnel on duty have two-way communications with all persons who may be endangered. Such signals shall be activated when the level of $\mathrm{CO}$ exceeds $10 \mathrm{ppm}$ above the ambient level of the mine. (g) The person at the manned location on the surface shall be trained in the operation of the $\mathrm{CO}$ monitoring system and in the proper procedures to follow in the event of an emergency.

2. At any time the CO monitor has been deenergized, for reasons such as power outages or routine maintenance, the belt conveyor may continue to operate. The belt entry shall be continuously patrolled and physically monitored by a qualified person with CO detector tubes or equivalent means until the monitor returns to normal operation.

3. The Co monitor and sensor shall be visually examined at least once every 24 hours to insure proper functioning. The unit shall be inspected by a qualified person for such work not less than every 7 days. The inspection shall insure the monitor is operating properly and that the required maintenance as recommended by the manufacturer is performed.

The monitor shall be calibrated with known quantities of $\mathrm{CO}$ and air mixtures at least every 30 calendar days. An inspection record shall be maintained on the surface and made available to all interested persons. The inspection record shall show the date and time of each weekly inspection and calibration of the monitor, and all maintenance performed, whether at the time of the weekly inspection or otherwise.

4. The details for the fire detection system including, but not limited to, type of monitor, sensor location, alarm system, maintenance, and calibration schedule shall be included as a part of the Ventilation System and Methane and Dust Control Plan required by 30 CFR 75.316. The District Manager may require additional $\mathrm{CO}$ monitors to be installed as part of said plan to insure the safety of the miners. 
5. The velocity of the air current in the belt entry shall not exceed $300 \mathrm{fpm}$.

6. The concentrations of respirable dust in the intake air passing over the belt conveyor shall be within the requirements of 30 CFR $70.100(\mathrm{~b})$.

7. The petitioner must continue to comply with all mandatory safety and health standards at this mine except as specifically modified by this Decision and Order.

Other guidelines are taken from "Equivalency Tests of Fire Detection Systems for Underground Coal Mines Using Low Leve1 Carbon Monoxide Monitors" (14). They include--

1. For contaminant travel velocities $200 \mathrm{fpm}$ or less, the Co monitors should not be spaced in excess of $2,000 \mathrm{ft}$, and not in excess of $3,000 \mathrm{ft}$ when contaminant travel velocities exceed $200 \mathrm{fpm}$.

2. In conveyor belt entries where the air velocity is less than $50 \mathrm{fpm}$ or the air stream does not have a definite and distinct direction, $\mathrm{CO}$ monitors may not be appropriate. 


\section{APPENDIX D.--POTENTIAL LOCATIONS FOR FIXED-POINT SENSORS}

\section{BASED ON 30 CFR PART 75 REQUIREMENTS}

CFR Part 75--Underground Coa1 Mine Standards were reviewed to determine $10^{-}$ cations where manual examinations of the mine environment are required to provide a healthy and safe workplace. When a mine installs a computerized monitoring system to monitor the environment, the locations required to be examined by 30
CFR for environmental hazards may also be appropriate for fixed-point monitoring. For the examinations currently required, this section reviews the location, the measurand, the regulation number, and the frequency of examination as a possibility for fixed-point monitoring.

TABLE D-1. - Potential locations for fixed-point sensors

\begin{tabular}{|c|c|c|c|c|c|c|c|}
\hline \multirow[t]{2}{*}{ Location } & \multicolumn{5}{|c|}{ Measurand ${ }^{l}$} & \multirow[t]{2}{*}{ Regulation } & \multirow[t]{2}{*}{ Frequency } \\
\hline & $\bar{Q}$ & $\mathrm{~V}$ & $\mathrm{CO}_{2}$ & $\mathrm{CH}_{4}$ & $\mathrm{CO}$ & & \\
\hline Main fans....... & - & - & - & - & - & 75.300 & Continuous ly. \\
\hline $\begin{array}{l}\text { A11 active } \\
\text { workings. }\end{array}$ & - & $>60$ & $<0.5$ & - & - & 75.301 & Periodic. \\
\hline $\begin{array}{l}\text { Inby end of } \\
\text { brattice face. }\end{array}$ & $>3,000$ & - & - & $<1$ & - & $\begin{array}{l}75.301 \\
75.307\end{array}$ & \\
\hline $\begin{array}{l}\text { Last open cross- } \\
\text { cut face. }\end{array}$ & $>9,000$ & - & - & $<1$ & - & $\begin{array}{l}75.301 \\
75.307\end{array}$ & $\begin{array}{l}\text { Prior to ma- } \\
\text { chine start- } \\
\text { up; every } 20 \\
\text { min during } \\
\text { mining. }\end{array}$ \\
\hline $\begin{array}{l}\text { Intake end--pil- } \\
\text { lar line. }\end{array}$ & $>9,000$ & - & - & $<1$ & - & $\begin{array}{l}75.301 \\
75.307\end{array}$ & \\
\hline $\begin{array}{l}\text { Intake end-- } \\
\text { longwall face. }\end{array}$ & $>9,000$ & - & - & $<1$ & - & $\begin{array}{l}75.301 \\
75.307\end{array}$ & \\
\hline Auxiliary fans.. & - & - & - & $<1$ & - & 75.302 & Continuously. \\
\hline Working sections & Yes & Yes & - & Yes & - & 75.303 & Preshift. \\
\hline Do........... & Yes & Yes & - & Yes & - & 75.304 & $\begin{array}{l}\text { Onshift ( } 1 \\
\text { per shift). }\end{array}$ \\
\hline $\begin{array}{l}\text { Each return } \\
\text { split at main } \\
\text { return. }\end{array}$ & Yes & Yes & - & Yes & - & 75.305 & Weekly. \\
\hline $\begin{aligned} \mathrm{l}_{\mathrm{Q}} & =\text { quantity } \\
\mathrm{V} & =\text { velocity } \\
\mathrm{CO}_{2} & =\text { carbon dic }\end{aligned}$ & $\begin{array}{l}\text { air, } \\
\text { air, } \\
\text { de. }\end{array}$ & $\begin{array}{l}\mathrm{m} . \\
\mathrm{m} . \\
\% \text {. }\end{array}$ & $\begin{array}{l}\mathrm{CH} \\
\mathrm{CO} \\
-\end{array}$ & $\begin{array}{l}=\text { met } \\
=\text { cal } \\
\text { dicat }\end{array}$ & vol & $\begin{array}{l}\text { vol } \% . \\
\text { inapp } 1\end{array}$ & \\
\hline
\end{tabular}


TABLE D-1. - Potential locations for fixed-point sensors--Continued

\begin{tabular}{|c|c|c|c|c|c|c|c|}
\hline \multirow[t]{2}{*}{ Location } & \multicolumn{5}{|c|}{ Measurand ${ }^{1}$} & \multirow[t]{2}{*}{ Regulation } & \multirow[t]{2}{*}{ Frequency } \\
\hline & Q & V & $\mathrm{CO}_{2}$ & $\mathrm{CH}_{4}$ & $\mathrm{CO}$ & & \\
\hline $\begin{array}{l}\text { Pillar falls and } \\
\text { seals at main } \\
\text { return. }\end{array}$ & Yes & Yes & - & Yes & - & 75.305 & Weekly • \\
\hline $\begin{array}{l}\text { l entry of each } \\
\text { intake and re- } \\
\text { turn aircourse, } \\
\text { in its } \\
\text { entirity. }\end{array}$ & Yes & Yes & - & Yes & - & 75.305 & Do. \\
\hline Idle workings.... & Yes & Yes & - & Yes & - & 75.305 & Do. \\
\hline Abandoned area... & Yes & Yes & - & $\begin{array}{l}\text { If } \\
\text { entered }\end{array}$ & - & $\begin{array}{l}75.305 \\
75.314\end{array}$ & $\begin{array}{l}\text { Week } 1 y \text {, with- } \\
\text { in } 3 \mathrm{~h} \text { of } \\
\text { entry. }\end{array}$ \\
\hline $\begin{array}{l}\text { Main intakes and } \\
\text { returns. }\end{array}$ & Yes & Yes & - & - & - & 75.306 & Week1y. \\
\hline Working sections. & Yes & Yes & - & - & - & 75.306 & Do. \\
\hline $\begin{array}{l}\text { Return air split } \\
\text { from working } \\
\text { section. }\end{array}$ & - & - & - & $<1$ & - & 75.309 & $\begin{array}{l}\text { 4-h interval } \\
\text { during } \\
\text { shift. }\end{array}$ \\
\hline Belt entries.... & & Neutral & - & $<1$ & $\begin{array}{l}\text { Under } \\
\text { variance }\end{array}$ & 75.326 & Periodic. \\
\hline Track entries.... & - & $<250$ & - & $<1$ & - & 75.327 & Do. \\
\hline $\begin{array}{l}\text { In intake between } \\
\text { abandoned area } \\
\text { and working } \\
\text { place. }\end{array}$ & - & - & - & $\begin{array}{l}<0.25 \text { if } \\
\text { used to } \\
\text { ventilate }\end{array}$ & - & $\begin{array}{l}75.311 \\
75.312\end{array}$ & Preshift. \\
\hline
\end{tabular}




\section{APPENDIX E.--CARBON MONOXIDE SENSOR SPACING CRITERIA} AS DEFINED BY FACTORY MUTUAL RESEARCH CORP.

Fire sensor spacing criteria were developed by Factory Mutual Research Corp. (FMRC) (18) based on a universal set of detection criteria defined relative to the application of fire detectors in underground mines. This required a time relationship to be established to detect a fire; the time to effectively respond after detecting a fire; and the time after the initiation of a fire to reach a defined hazard, $t_{H}$, the hazard time, such as a fire that becomes seriously life threatening. Three main fire scenarios were considered by FMRC: (1) a coal fire in a conveyor belt haulageway that served as the ignition source for the belting, (2) a coal wall fire, and (3) a wood wall fire.

For the beltway fire (scenario 1), both equivalent spacing prescribed by $30 \mathrm{CFR}$ and generalized spacing for fire detectors were determined. Since equivalent spacing is a function of the mine geometry and ambient conditions, a "typical" beltway configuration was assumed as given in table E-1. Table E-2 gives

TABLE E-1. - Typical conditions in a conveyor belt haulageway

Ambient temperature......... ${ }^{\circ} \mathrm{F} .$. Ventilation rate............cfm.. 4,000

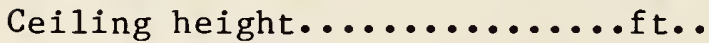

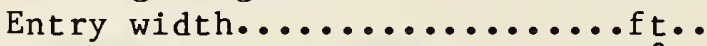
Cross-sectional area.........ft ${ }^{2}$.. Ambient velocity............fpm..
(1) detector type, (2) alarm and/or alert level, (3) equivalent spacing, (4) safety parameter, $X$, and (5) the corresponding spacing for each detector at $X>0.50$, for each detector tested by FMRC. The safety parameter, $X$, is the time available for response to the fire after detection and is a fraction of the hazard time. The larger the value of $X$, the more time is available. Equivalent spacing was assessed using $X$, such that the spacing for a nonheat detector was determined at the minimum safety parameter given by a mine-permissible heat detector, i.e., $X=0.45$. The recommended maximum spacing for each detector is given for $X>0.50$ and ranges from $10 \mathrm{ft}$ for the slowest heat detector to $1,000 \mathrm{ft}$ for the fastest product-of-combustion detector.

Tables E-3, E-4, and E-5 give the generalized spacing criteria for each fire scenario considered. In each table the spacing criteria ( $S$ ) are listed versus $V$ (the ventilation rate in $1,000 \mathrm{cfm}$ ) and $X$ (the safety parameter). The procedure for determining the sensor spacing distance follows:

1. Select values of $X$ and $V$.

2. Read the corresponding value of $S$ in the table for the scenario of interest.

3. Calculate the spacing distance from spacing distance $(f t)=(V(S-43)) / 60$.

TABLE E-2. - Equivalency for fire detectors for beltway fires

\begin{tabular}{|c|c|c|c|c|c|}
\hline Detector & Type & Alarm and/or alert level & $\begin{array}{l}\text { Equivalent } \\
\text { spacing, ft }\end{array}$ & $\mathrm{X}$ & $\begin{array}{l}\text { Recommended max } \\
\text { spacing, ft }\end{array}$ \\
\hline$\overline{\text { Ideal. }}$ & Heat & $\triangle 39^{\circ} \mathrm{C} \ldots$ & 50 & 0.70 & 180 \\
\hline Thermot & Heat & $\Delta 35^{\circ} \mathrm{C} \ldots$ & 50 & .70 & 180 \\
\hline MSA..... & Heat & $\Delta 39^{\circ} \mathrm{C} \ldots \ldots \ldots$ & 50 & .65 & 150 \\
\hline Pyott-Boone & Heat & $\Delta 37^{\circ} \mathrm{c} \ldots \ldots \ldots \ldots \ldots$ & 50 & .45 & 10 \\
\hline Ecolyzer.. & $\mathrm{CO}$ & $\Delta 10 \mathrm{ppm} / 5 \mathrm{ppm}^{*} \ldots \ldots$ & 980 & .45 & 870 \\
\hline MSA....... & $\mathrm{CO}$ & $\Delta 10 \mathrm{ppm} / 5 \mathrm{ppm}^{*}$. & 980 & .45 & 870 \\
\hline Spanair..... & $\mathrm{CO}_{2}$ & $\Delta 200 \mathrm{ppm} / 100 \mathrm{ppm}^{*} \ldots$ & 430 & .45 & 310 \\
\hline Becon........... & Smoke & $0.05 \mathrm{~m}^{-1} / 0.025 \mathrm{~m}^{-1 *} \ldots \ldots$ & 1,100 & .45 & 1,000 \\
\hline
\end{tabular}

${ }^{*}$ Suggested levels. 
The value 43 in the equation is a typical CO sensor response time (in seconds) as determined through FMRC testing.
Further information on the FMRC work can be obtained from the final report (18).

TABLE E-3. - Spacing criteria (S) for carbon monoxide sensors for beltway fires ${ }^{1}$

\begin{tabular}{c|c|c|c|c||r|r|r|c|c}
\hline Velocity, & \multicolumn{4}{|c|}{ Safety factor } & \multicolumn{3}{|c|}{ Velocity, } & \multicolumn{3}{c}{ Safety factor } \\
\cline { 2 - 9 } 1,000 cfm & $X=0$ & $X=0.25$ & $X=0.50$ & $X=0.75$ & 1,000 cfm & $X=0$ & $X=0.25$ & $X=0.50$ & $X=0.75$ \\
\hline 0 & 2,700 & 2,030 & 1,350 & 680 & 7 & 2,350 & 1,670 & 1,000 & 330 \\
1 & 2,570 & 1,890 & 1,220 & 550 & 8 & 2,320 & 1,650 & 970 & 300 \\
2 & 2,510 & 1,840 & 1,160 & 490 & 9 & 2,200 & 1,620 & 950 & 280 \\
3 & 2,470 & 1,790 & 1,120 & 450 & 10 & 2,280 & 1,600 & 930 & 260 \\
4 & 2,430 & 1,760 & 1,080 & 410 & 11 & 2,260 & 1,580 & 910 & 240 \\
5 & 2,400 & 1,730 & 1,050 & 380 & 12 & 2,240 & 1,560 & 890 & 220 \\
6 & 2,370 & 1,700 & 1,020 & 350 & & & & & \\
\hline
\end{tabular}

${ }_{t_{H}}=2,700 \mathrm{~s}$.

TABLE E-4. - Spacing criteria (S) for carbon monoxide sensors for coal wall fires

\begin{tabular}{c|c|r|r|r|r}
\hline Velocity, & \multicolumn{1}{c|}{$t \mathrm{H}}$, & \multicolumn{4}{|c}{ Safety factor } \\
\cline { 3 - 6 } 1,000 cfm & \multicolumn{1}{c}{$\mathrm{s}$} & $\mathrm{X}=0$ & $\mathrm{X}=0.25$ & $\mathrm{X}=0.50$ & $\mathrm{X}=0.75$ \\
\hline 0 & 0 & 1 & 0 & 0 & 0 \\
1 & 1,630 & 1,500 & 1,090 & 680 & 280 \\
2 & 2,300 & 2,110 & 1,530 & 960 & 390 \\
3 & 2,820 & 2,590 & 1,880 & 1,180 & 480 \\
4 & 3,250 & 2,990 & 2,170 & 1,360 & 550 \\
5 & 3,640 & 3,340 & 2,430 & 1,520 & 610 \\
6 & 3,980 & 3,660 & 2,660 & 1,670 & 670 \\
7 & 4,300 & 3,950 & 2,870 & 1,800 & 730 \\
8 & 4,600 & 4,230 & 3,070 & 1,920 & 780 \\
9 & 4,880 & 4,490 & 3,260 & 2,040 & 830 \\
10 & 5,140 & 4,730 & 3,430 & 2,150 & 870 \\
11 & 5,390 & 4,960 & 3,600 & 2,250 & 910 \\
12 & 5,630 & 5,180 & 3,760 & 2,360 & 950 \\
\hline
\end{tabular}

TABLE E-5. - Spacing criteria (S) for carbon monoxide sensors for wood wall fires

\begin{tabular}{c|r|r|r|r|c}
\hline Velocity, & \multicolumn{1}{c|}{$\begin{array}{c}\mathrm{S}, \\
\mathrm{S}\end{array}$} & \multicolumn{4}{|c}{ Safety $\mathrm{factor}$} \\
\cline { 3 - 6 } $\mathrm{X}=0$ & $\mathrm{X}=0.25$ & $\mathrm{X}=0.50$ & $\mathrm{X}=0.75$ \\
\hline 0 & 0 & 0 & 0 & 0 & 0 \\
1 & 450 & 290 & 180 & 70 & 0 \\
2 & 630 & 400 & 250 & 90 & 0 \\
3 & 770 & 490 & 300 & 110 & 0 \\
4 & 890 & 570 & 350 & 130 & 0 \\
5 & 1,000 & 640 & 390 & 150 & 0 \\
6 & 1,090 & 700 & 430 & 160 & 0 \\
7 & 1,180 & 750 & 460 & 170 & 0 \\
8 & 1,260 & 810 & 490 & 180 & 0 \\
9 & 1,340 & 860 & 530 & 200 & 0 \\
10 & 1,420 & 900 & 550 & 210 & 0 \\
11 & 1,480 & 950 & 580 & 220 & 0 \\
12 & 1,540 & 990 & 610 & 230 & 0 \\
\hline
\end{tabular}






\section{AN EQUAL OPPOATUNITY EMPLOYER \\ AN EQUAL}

\author{
U.S. Department of the Interior
Bureau of Mines-Prod. and Distr. \\ U.S. Department of the Interior
Bureau of Mines-Prod. and Distr. \\ Cochrans Mill Road \\ P.O. Box 18070 \\ Pittsburgh, Pa. 15236 \\ OFFICIAL gLSINESS
Do not wish to receive this
naterial, please remove
rom your mailing list.
Address change. Please \\ OFFICIAL gLSINESS
PENALTYOA PRIVATE USE, $\$ 300$
Do not wish to receive this
material, please remove
from your mailing list.
Address change. Please \\ OFFICIAL gLSINESS
PENALTYOR PAIVATE USE, $\$ 300$
Do not wish to receive this
material, please remove
from your mailing list.
Address change. Please \\ OFFICIAL gLSINESS
PENALTYOR PAIVATE USE, $\$ 300$
Do not wish to receive this
material, please remove
from your mailing list.
Address change. Please \\ OFFICIAL gLSINESS
PENALTYOR PAIVATE USE, $\$ 300$
Do not wish to receive this
material, please remove
from your mailing list.
Address change. Please \\ OFFICIAL gLSINESS
PENALTY FOR PAIVATE USE, $\$ 300$
Do not wish to receive this
material, please remove
from your mailing list.
Address change. Please \\ correct as indicated.
}

.
(n)

\author{
correct as indicatedo
}

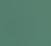

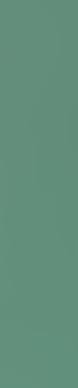

\title{
(2)
}





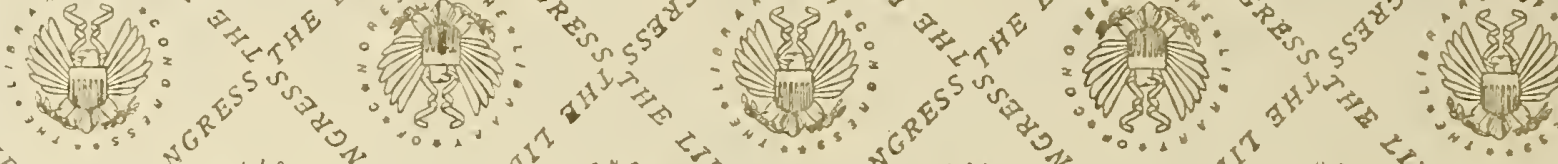

.

m (E)

ald

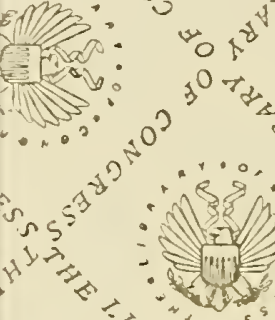

tis

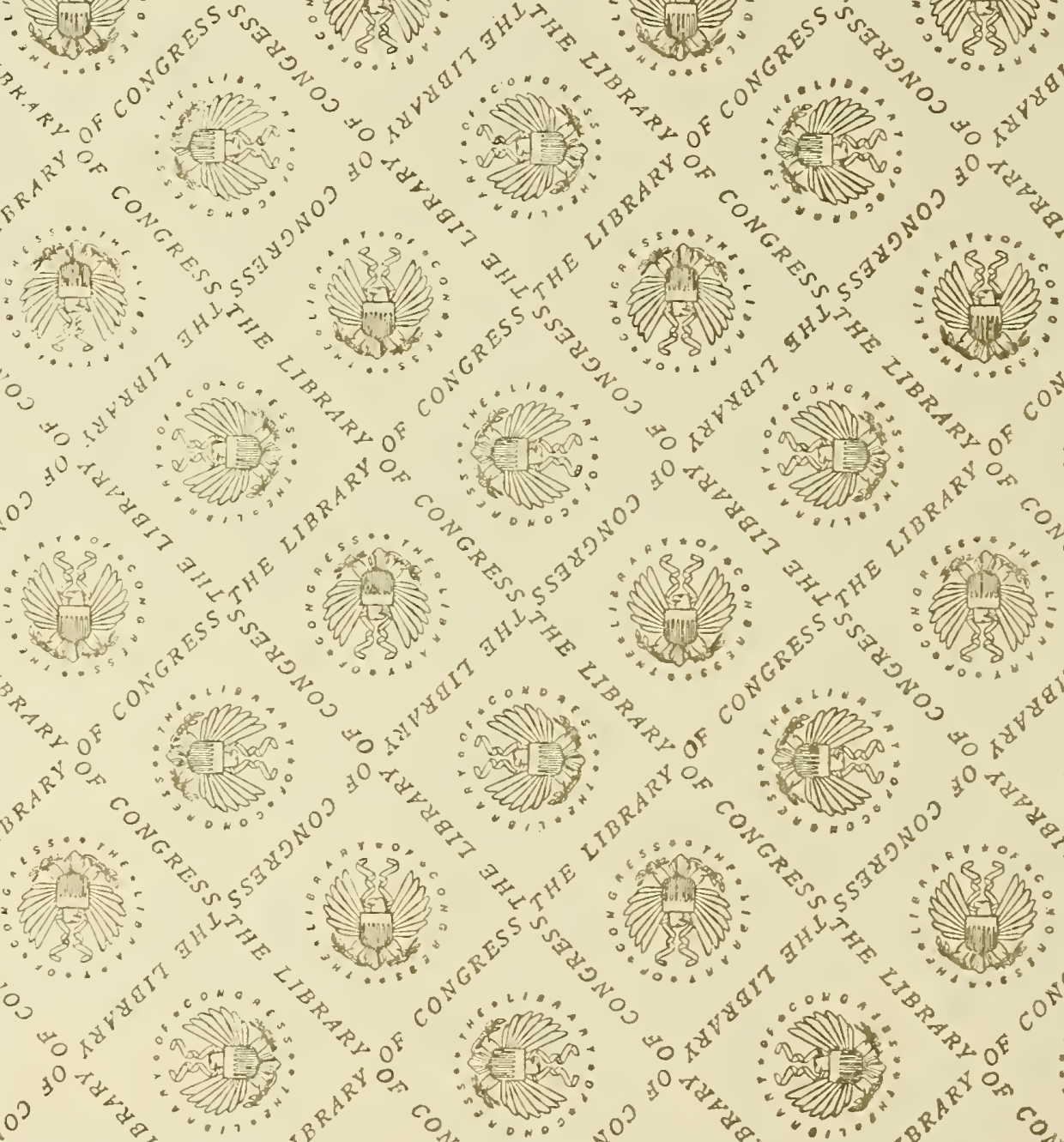

. 10

"

$7=$

tens

a

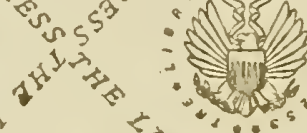

and

alu

$3^{0}+\frac{1}{\alpha_{2}}$

$4^{40}+0^{4}$

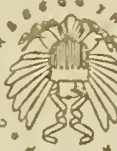




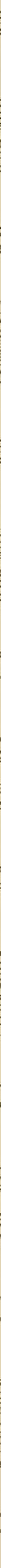


LIBRARY OF CONGRESS

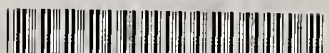

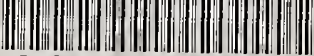

00029510295 